\title{
Sex Differences in Health and Survival
}

\author{
Anna Oksuzyan, Jordi Gumà and Gabriele Doblhammer
}

\section{Sex Differences in Survival}

Empirical research has shown that being male is the most consistent predictor of mortality at all ages in all countries of the world (Barford et al. 2006). A female survival advantage was reported as far back as the 1750s (Glei and Horiuchi 2007). As the economic and living conditions of women in many parts of the world improved dramatically from the 1950s to the mid-1970s, the gender gap also widened rapidly in countries such as Canada, New Zealand, Australia, Japan, and most European (EU) countries, including countries in eastern Europe (Glei and Horiuchi 2007; Rigby and Dorling 2007; Oksuzyan et al. 2008). During this period, the gender gap in survival chances in the US continued to increase despite the convergence of mortality differentials across other socio-demographic characteristics, such as place of residence (urban versus rural), ethnicity (white versus non-white), and socioeconomic status (Madigan and Vance 1957). However, the

\footnotetext{
A. Oksuzyan $(\bowtie) \cdot$ G. Doblhammer Max Planck Institute for Demographic Research, Rostock, Germany e-mail: oksuzyan@demogr.mpg.de

G. Doblhammer

e-mail: gabriele.doblhammer@uni-rostock.de

J. Gumà

Department of Political and Social Sciences, University Pompeu Fabra, Barcelona, Spain

e-mail: jordi.guma@upf.edu

G. Doblhammer

Faculty of Economics and Social Sciences, Institute of Sociology and Demography,

University of Rostock, Rostock, Germany

(C) The Author(s) 2018

G. Doblhammer and J. Gumà (eds.), A Demographic Perspective on Gender,

Family and Health in Europe, https://doi.org/10.1007/978-3-319-72356-3_5
} 
trends in sex differences in mortality in these countries were mixed in the last quarter of the 20th century. A narrowing trend was first observed in England and Wales in the early 1970s, then in other English-speaking countries in the late 1970s and the early 1980s, and slightly later in the Scandinavian countries, Austria, and the Netherlands (Trovato and Heyen 2006; Glei and Horiuchi 2007). From the 1980s to the late 1990s, the female-male differences in life expectancy narrowed in most EU countries and in the US, but expanded in certain countries, such as Greece, Hungary, and Japan (Waldron 1993; Gjonca et al. 2005). Across the developed countries, figures for 2013 indicate that the gender gap in life expectancy was largest in the Russian Federation (11.19 years) and smallest in Ireland (3.07 years) (HMD).

There are, however, fewer studies that have looked at the extent to which life expectancy at older ages differs by gender, and at how these gaps have changed over time across developed countries (Thorslund et al. 2013). The sex differences in life expectancy at age 65 , when the impact of infant mortality and mortality related to reproduction (women) and high-risk behavior (men) are reduced, have been found to follow similar trends across 17 wealthy low-mortality countries, albeit with differences in timing (Thorslund et al. 2013). Until the 1950s, the gender gap in mortality in these countries was small, at around one year. But from the 1950s to the 1980s, the gap widened in most countries, to around four years. Since then, the gender gap in mortality has been narrowing in all but two countries, Japan and Spain.

Trajectories of sex differences in mortality have varied substantially across age groups and causes of death in different EU countries and over different time periods. Prior to World War II, reductions in infant mortality contributed substantially to the widening of sex differences in life expectancy (Vallin 2006). Since 1950, these differences have been mostly attributable to mortality trends at adult ages and to the causes of deaths closely related to lifestyle and health behaviors; e.g., ischemic heart disease, lung cancer, liver cirrhosis, traffic accidents, and suicide (Waldron 1993; Trovato and Heyen 2006; Glei and Horiuchi 2007; Oksuzyan et al. 2008). There is growing evidence that cigarette smoking is the factor that has played the largest role in the sex differential mortality (Preston and Glei 2011; Martikainen et al. 2014; Beltrán-Sánchez et al. 2015; Lindahl-Jacobsen et al. 2016). However, smoking alone cannot explain these trajectories, as a female advantage in life expectancy has also been observed among nonsmokers and specific populations, such as Mormons (Wingard et al. 1983; Rogers and Powell-Griner 1991; Lindahl-Jacobsen et al. 2013).

A variety of studies have provided convincing evidence that a female advantage in healthy life expectancy is less apparent [reviewed in (Oksuzyan et al. 2010a)]. Although women live longer with activity limitations at ages 15 and 50, the gender gap in healthy life expectancy is smaller than the gender gap in life expectancy in most EU countries (Van Oyen et al. 2010; Van Oyen et al. 2012). These findings suggest that women may more likely to survive despite having disabilities and chronic conditions than men. 


\section{Sex Differences in Health}

\section{Sex Differences in Physical Performance Tests}

Physical performance measures have been routinely used in clinical assessments. Because handgrip strength test, gait speed test, and physical performance battery test (standing balance, gait speed, and chair rises) are quick, inexpensive, and easy to administer and are shown to be valid and reliable tools for assessing muscle strength (Mijnarends et al. 2013), they are often included in data collection instruments of population-based surveys (Innes 1999; Roberts et al. 2011).

It has been suggested that handgrip strength is a better marker of frailty than chronological age (Syddall et al. 2003), and it predicts all-cause and cause-specific mortality in community-based and patient populations (Fujita et al. 1995; Rantanen et al. 2000; Sasaki et al. 2007; Ling et al. 2010; Ortega et al. 2012; Leong et al. 2015). Moreover, handgrip strength has been found to be associated with disability at older ages (Giampaoli et al. 1999; Rantanen et al. 1999; Taekema et al. 2010), cognitive decline (Alfaro-Acha et al. 2006), and hospitalization (Cawthon et al. 2009). While there is compelling evidence that men outperform women on handgrip tests at all ages and across all continents (Bohannon et al. 2006; Dodds et al. 2014; Leong et al. 2015), the magnitude of the male advantage appears to vary across national populations, ethnicities, and age groups. It is remarkable that the grip strength of an 80-year-old Danish man is similar to that of a 45-year-old Danish woman (Frederiksen et al. 2006). The evidence that men tend to outperform women on grip strength performance seems to be inconsistent with the higher deaths rates among men at all ages. In one study that examined this apparent contradiction, the authors hypothesized that men and women differ not only in their initial grip strength levels, but also in the pace at which their grip strength declines with age. Thus, they suggested that the sex-specific associations of these parameters with lifespan may partially explain sex differences in health and mortality (Oksuzyan et al. 2010c). The results of the study indicated that men have higher initial levels of and a steeper decline in grip strength, but that the initial level was more strongly associated with lifespan than the age-related decline. These predictive effects were found to be similar in men and women.

Gender differences in other physical capability tests, such as chair rises, walking speed (or gait speed), timed get up and go (TUG), and standing balance were investigated in several cohort studies in the UK (Cooper et al. 2011; Keevil et al. 2013). Large male advantages were found for chair rising ability and standing balance, but no sex differences were observed for TUG and walking speed.

Findings on age variations in gender differences on physical performance tests have been less conclusive. Butler et al. reported that young people had similar performance levels on seven physical tests, but that older women had lower normative values than men of the same age (Butler et al. 2009). The male-female difference in grip strength was shown to increase with advancing age in the European Prospective Investigation into Cancer (EPIC)-Norfolk study, whereas a 
meta-analysis of eight other UK cohort studies indicated that gender differences diminished with advancing age for grip strength; did not change for TUG, chair rising ability, and standing balance; and increased for walking speed (Cooper et al. 2011; Keevil et al. 2013). These mixed patterns can be partially explained by differences in the sex-specific mortality selection in the background populations and by differences in drop-out rates due to non-response and due to the inability to perform the test across surveys (Cooper et al. 2011).

\section{Sex Differences in Cognitive Function}

The topic of gender differences in cognitive function continues to attract considerable attention from the scientific, the medical, and the political communities. Generally, the results of empirical research have suggested that men have advantages in mathematical and visuospatial abilities (Linn and Petersen 1985; Voyer et al. 1995; Halpern et al. 2016), that women have advantages in episodic memory (Halpern et al. 2016; Herlitz and Rehnman 2008) and verbal ability (Hyde and Linn 1988; Reilly 2012), and that there are no significant sex differences in category fluency (Crossley et al. 1997). Recent studies conducted in more gender-egalitarian societies have found smaller gender differences in levels of mathematical achievement (Guiso et al. 2008; Else-Quest et al. 2010; Lindberg et al. 2010). Gender differences in cognitive tasks have been found to be stable from adulthood to old age, which suggests that age-related declines in cognitive abilities have similar trajectories in men and women (Barnes et al. 2003; de Frias et al. 2006; Gerstorf et al. 2006). With respect to general intelligence, most researchers have found no or negligible sex differences in adolescent and adult populations in developed countries (Aluja-Fabregat et al. 2000; Colom et al. 2000; van der Sluis et al. 2006; Burgaleta et al. 2012).

Empirical research has consistently demonstrated that poor cognitive function is associated with increased mortality risk in older populations (Gale et al. 1996; Pavlik et al. 2003; Perna et al. 2015). In contrast, studies on predictive abilities of cognitive decline beyond current levels of cognitive function have reached competing conclusions (Maier et al. 2003; Schupf et al. 2005; Ghisletta 2008; Lavery et al. 2009). The question of whether there are sex-specific protective effects of various cognitive abilities for health and mortality also warrants further investigation.

In seeking to explain gender differences in cognitive abilities, some scholars have cited societal factors, cultural differences, and gender stereotypes; as well as biological factors, such as differences in prenatal hormonal influences and brain size and structure (Ankney 1992; Alonso-Nanclares et al. 2008; Rushton and Ankney 2009; Tapp et al. 2011; Miller and Halpern 2014). In light of evidence showing that these differences vary substantially across nations, and mirror the gender inequalities in education, employment opportunities, and career achievements in particular 
countries, researchers have suggested that improved standards of living and educational opportunities in populations with lower economic development levels may improve the cognitive performance levels in these populations, especially among women (Baker and Jones 1993; Else-Quest et al. 2010; Weber et al. 2014).

\section{Sex Differences in Depression}

A growing body of literature has indicated that women are more likely than men to suffer from depression, although the direction and the magnitude of these sex differences have been shown to vary across diagnostic subtypes and age (Piccinelli and Wilkinson 2000). Gender disparities have been found in the prevalence of somatic symptoms of depression, with women being more prone to experience symptoms such as appetite disturbance, sleep disorders (Roberts et al. 2000; Kockler and Heun 2002; Jaussent et al. 2011), and atypical depression (Angst et al. 2002); and men being substantially more likely than women to experience the most tragic consequence of depression: suicide (Bjerkeset et al. 2008; Brådvik et al. 2008).

A number of studies have shown that gender disparities in depression increase after early to mid-adolescence, and are especially large at reproductive ages (Nolen-Hoeksema and Girgus 1994; Hankin et al. 1998; Grigoriadis and Erlick Robinson 2007). Generally, it appears that women are more likely than men to suffer from depression though old age as well (Cairney and Wade 2002; Djernes 2006). Other studies have shown that sex differences in the prevalence of depression reverse after menopause (Bebbington et al. 1998), or become smaller at older ages (Barefoot et al. 2001; Djernes 2006; McDougall et al. 2007). These findings, which remain controversial, may be attributable to the geographic differences and the methodological challenges inherent in large-scale community-based studies of oldest-old individuals. Among these challenges are the failure to include residents of long-term care facilities, attrition due to non-response and death, and differences in the instruments used to measure depression symptomatology.

There are a number of hypotheses to explain the female preponderance in depression, including (1) artefacts, such as differential treatment-seeking and symptom-reporting behavior; (2) biological differences due to ovarian hormonal changes during puberty, postpartum periods, and menopause, and to changes in adrenal hormone levels in reaction to stressful events; (3) social factors, such as social pressure, abuse experiences during puberty and at work, role overload related to pressure to balance working full time with managing care responsibilities for children and elderly parents; and (4) psychological factors, such as having low self-esteem, low self-confidence, and high levels of neuroticism, and a greater tendency to engage in rumination (Nolen-Hoeksema and Girgus 1994; Nolen-Hoeksema 2001; Kuehner 2003; Hyde et al. 2008). Since most studies that examine the gender gap in depression focus on disentangling the effects of 
individual factors that contribute to this gap, there is a need for more integrative models that account for multiple pathways in the development of depression, and for the interactions of these individual factors. Understanding gender differences in depression may allow policy-makers to formulate strategies for improving women's quality of life and productivity, thereby reducing the health care costs associated with treating depression. Moreover, identifying the sources of this gender gap could help researchers better understand the origins of depression and dementia.

\section{Sex Differences in Morbidity}

The issue of sex differences in morbidity is multifaceted because the direction and the magnitude of sex differences in morbidity may vary depending on the particular disease or chronic condition under investigation, the age-related changes in the incidence rates of the disease, and the sex-specific rates of survival after the onset of the disease. It has been shown that women tend to report more symptoms and have a greater number of comorbidities that are not lethal but are disabling, whereas men have more life-threatening conditions (Macintyre et al. 1996; Case and Paxson 2005; Crimmins et al. 2011). This pattern was found in a study on opposite-sex twins that controlled for early environmental and genetic factors. Specifically, the findings indicated that men had higher rates than women of heart insufficiency, angina pectoris, and stroke; and that women had higher rates than men of cataract, knee and hip problems, and urinary tract disorders (Gold et al. 2002). There is also some evidence that the sex-specific distribution of chronic conditions is reflected at the level of biological markers of health (Oksuzyan et al. 2015). Thus, excessive morbidity in women depends to a large extent on a selected disease or illness indicator. In this chapter, we are unable to provide a comprehensive review of the patterns of sex differences for all diseases. Instead, we offer an overview of the gender gaps for the most common chronic conditions and causes of death in developed countries (Dodds et al. 2012; Go et al. 2013).

The empirical evidence has suggested that compared to men, women tend to develop cardiovascular diseases (CVD) about ten years later and to have a lower lifetime risk of CVD (Jousilahti et al. 1999; Lawlor et al. 2001; Go et al. 2013). It has also been shown that the gender gap in the incidence of coronary heart disease (CHD) and stroke diminishes with advancing age (Lerner and Kannel 1986; Petrea et al. 2009). A substantial share of the sex differences in CVD incidence can be explained by differences in the distribution among men and women of major CVD risk factors, such as smoking, HDL cholesterol levels, and hypertension; and by age-related changes in these factors (Jousilahti et al. 1999; Freedman et al. 2004; Cutler et al. 2008).

The findings regarding sex differences in survival after myocardial infarction (MI) and stroke have been less consistent. Several studies have indicated that shortand long-term post-MI (Koek et al. 2006; Milcent et al. 2007) and post-stroke mortality is higher in women than in men (Appelros et al. 2009; Lewsey et al. 2009; 
Appelros et al. 2010; Andersen et al. 2011). Some studies found that the female disadvantage in post-stroke survival was limited to younger ages (Vaccarino et al. 1998, 1999, 2001; Nielsen et al. 2014), while others found that rates of post-MI and post-stroke survival did not differ significantly by gender after the baseline and clinical characteristics were taken into account (Galatius et al. 1996; Herman et al. 1997; MacIntyre et al. 2001; Di Carlo et al. 2003; Isaksson et al. 2011; Olsen et al. 2012).

Sex differences in post-stroke survival have been shown to vary across stroke types: studies have found that at younger ages ischemic and intracerebral hemorrhagic stroke deaths are less common among women than among men, but that ages 65+ women are less likely than men to survive an ischemic stroke (Ayala et al. 2002). Compared to men, women are more likely to experience post-stroke depression and functional disabilities, to be institutionalized, and to have a poor quality of life (Di Carlo et al. 2003; Roquer et al. 2003; Appelros et al. 2009; Petrea et al. 2009).

Scholars seeking to explain these controversial findings on sex differences in post-stroke and post-MI health outcomes have speculated that these disparities could be attributable to sex-specific MI mortality prior to hospitalization; or to gender differences in the severity of the disease, in the prevalence of comorbid conditions, and in the treatment strategies used (Blomkalns et al. 2005). Strokes and MI have been found to be more severe in female than male populations (Appelros et al. 2009; Olsen et al. 2012). However, these findings have been challenged in the literature, and appear to vary depending on the measures used to define disease severity (Iezzoni et al. 1997; Barrett et al. 2007; Kardys et al. 2007; Reeves et al. 2008). Gender differences in pre-existing conditions may also contribute to survival after MI and stroke. A history of hypertension and atrial fibrillation was found to be more common among female patients who survived stroke than among their male counterparts, while a history of ischemic heart disease and diabetes was shown to be more prevalent among male than among female patients (Holroyd-Leduc et al. 2000; Di Carlo et al. 2003). In a study that compared diabetic and non-diabetic patients, the overall relative risk of dying of CHD was found to be substantially greater among women than among men (Huxley et al. 2006). This result suggests that in addition to the differences in the distribution of comorbid conditions, the relative risk associated with a comorbidity may help to explain the gender differences in the prognoses for MI and stroke. Moreover, considerably more men than women undergo invasive cardiac procedures and receive aggressive treatment (Bowling et al. 2001; Shaw et al. 2004; Blomkalns et al. 2005; Smith et al. 2009). The marked differences observed in the treatment strategies for men and women have been partially explained by differences in disease severity, comorbid conditions, symptom presentation, and patient preferences for surgical or less aggressive forms of treatment (Vaccarino et al. 2003; Anand et al. 2005). However, more research is needed to help us better understand how these factors and treatment-seeking behaviors contribute to sex differences in survival after stroke and MI. 
A male preponderance in the incidence of cancer has been documented worldwide. Age-standardized incidence rates in EU countries in 2012 for all cancers (excluding non-melanoma skin cancers) was 430 and 306 per 100,000 among men and women, respectively (Ferlay et al. 2013). The Cancer Incidence in Five Continents data, which cover around 60 countries, revealed that for 32 out of 35 sites men had higher incidence rates than women, with the largest gap being for cancer of the larynx (IRR $=6.36$ ), and the smallest gap being for other endocrine cancers $($ IRR $=1.19)$ (Edgren et al. 2012). A female disadvantage in cancer incidence was found for only a few sites: i.e., for Hodgkin's disease and for cancers of the thyroid, gallbladder, biliary tract, and anus (Edgren et al. 2012; Ferlay et al. 2013). A study for the US found that from 1975 to 2004 total cancer incidence was $37 \%$ higher among men than among women across all ages, and was $77 \%$ higher when sex-specific sites were excluded (Cook et al. 2009). Some variation in sex differences in cancer incidence across all ages was observed: for example, during the period 1975-2004, women under age 50 had higher incidence rates of all cancers and of cancers excluding sex-specific sites, whereas women over age 60 had lower incidence rates of both all cancers and cancers excluding sex-specific sites (Cook et al. 2009). When sex-specific sites and breast cancer were excluded, the total cancer rates were higher among men than among women aged 30 and older.

The age-standardized mortality rates (ASMRs) for all cancers and most cancer sites were found to be substantially higher in men than in women (Cook et al. 2011; Ferlay et al. 2013). In 2012, the ASMRs in Europe for all cancers (excluding non-melanoma skin cancers) were 223 and 129 per 100,000 among men and women, respectively. Women had higher ASMRs for cancers of the anus, the anal canal, the anorectrum, and the gallbladder, and no consistent gender patterns were observed for cancers of the peritoneum, the omentum, the mesentery, and the endocrine system. Empirical research has also shown that 5-year relative survival that cannot be explained by underlying sex differences in mortality is also higher in women than in men (Micheli et al. 1998; Albano et al. 2007). The average 5-year relative survival in Europe for eight major cancer sites (lung, melanoma, Hodgkin's disease, colorectal, breast, ovary, testis, and prostate) was found to be about $45 \%$ (44.6-45.0\%) for men and 55\% (54.4-54.8\%) for women (Berrino et al. 2007).

These sex disparities in cancer incidence have been attributed to a range of factors, including gender differences in genetic traits, steroid hormone levels, immunocompetence, and antioxidative abilities; as well as to a range of environmental factors, such as smoking and diet, occupational exposures, and sexual practices (Cook et al. 2009; Dorak and Karpuzoglu 2012; Edgren et al. 2012). Although cancer etiology has been studied for decades, we still do not fully understand the risk factors for cancer or their mechanisms. As the known risk factors cannot fully explain the sex disparities in cancer incidence for 13 out of 35 sites, it is important that research in this area continue (Edgren et al. 2012). The reasons for and the underlying mechanisms of sex differences in survival after cancer diagnosis also remain largely unknown. While the finding that the male disadvantage in cancer-specific survival attenuates after adjusting for cancer stage and grade suggests that these factors partially account for sex disparities, the extent to which sex 
differences in health care utilization and comorbidities explain sex differences cancer-specific survival rates has yet to be determined (Cook et al. 2011).

\section{Sex Differences in Self-perceived Health}

For two reasons, self-perceived health is the most studied and most frequently used indicator of subjective health. First, the association between self-perceived health and mortality has been well established (McGee et al. 1999; Singh-Manoux et al. 2007). Second, it is simple and easy to include question about overall health in both health-specific surveys such as the Survey of Health, Ageing and Retirement in Europe (SHARE) and the European Health Survey, and in more general surveys such as the European Statistics on Income and Living Conditions (EU-SILC-SILC) and the European Social Survey (ESS). Because this indicator is widely used in population health studies, Jylhä proposed a conceptual model for self-perceived health designed to enhance our understanding of the different factors that may influence an individual's perception of his or her health (2009). This model is composed of three main contextual frameworks that can modify an individual's evaluation of health: differences in conceptions of health (what is good and what is poor), the reference groups chosen for comparison (external counterparts with similar socio-demographic features, and internal expectations regarding health and aging), and cultural conventions regarding the expression of opinions (positive or negative).

Multiple studies have demonstrated that at all ages, women are more likely than men to report being in poor health (Crimmins et al. 2011; Crimmins and Salto 2001; Dahlin and Härkönen 2013). Three main reasons are usually given for this gender gap: gender differences in morbidity profiles, sex differences in health reporting, and gender differences in social determinants of health. The first reason is based on the observation that women are more likely than men to have chronic conditions linked to functional capacities, whereas men are more likely than women to have chronic conditions directly linked to survival, such CVD (Case and Paxson 2005). The second reason is based on evidence that women are more knowledgeable than men about their own health status, and that men are more likely than women to avoid going to the doctor or to admit their own vulnerability (Benyamini et al. 2000; Idler 2003). The last reason is explained in more detail later in this chapter.

A number of comparative studies of EU countries found that the southern and eastern EU countries had the highest gender gaps in self-rated health (Zambon et al. 2006; Eikemo et al. 2008; Crimmins et al. 2011). One of the main explanations for these cross-country differences is rooted in levels of gender equity: the higher the degree of gender inequity in a country, the larger the gender gap in self-perceived health (Zambon et al. 2006; Eikemo et al. 2008; Crimmins et al. 2011). However, the existing evidence on this issue is inconclusive. Dahlin and Härkönen in 2013 provided no support for this hypothesis, as they found that countries in both northern and southern Europe-like Sweden and Spain - have similar gender gaps in self-perceived health (Dahlin and Härkönen 2013). The authors also showed that 
the odds of reporting poor health are similar for men and women after controlling for other health indicators, such as chronic conditions and indicators of functioning. After these controls were applied, the gender differences in reporting poor health not only disappeared in the majority of countries, but even reversed in some countries (Crimmins et al. 2011; Dahlin and Härkönen 2013). These findings emphasize that the abovementioned unequal health profiles of men and women are influenced by their own perceptions, and thus call for additional explanations considering gender differences in health reporting.

\section{Sex Differences in Functional Status}

Functional status can be assessed using a wide range of indicators, with the most extensively used being Activities of Daily Living (ADL) and Instrumental Activities of Daily Living (IADL). ADL are all of the activities related to an individual's capacity to take care of his or her own basic needs, such as bathing, feeding, and dressing. IADL are the activities that allow an individual to live independently in a community context, such as shopping, managing money, and using the telephone. In this chapter, we focus on age-related functional limitations as a consequence of a progressive decline over an individual's life course; i.e., on limitations resulting from the "disablement process" proposed by Verbrugge and Jette, rather than on functional limitations at younger ages, which are likely to be of a different nature (1994).

A variety of studies have provided consistent evidence that men report having fewer difficulties in performing ADL and IADL than women (Newman and Brach 1999; Murtagh and Hubert 2004; Palacios-Cena et al. 2012). However, recent empirical research suggests that a female disadvantage in functional limitations is not apparent at all ages. Analyzing individuals from the British 1946 cohort, Murray et al. found that men and women are equally likely to have limitations at age 43, but that the gender differences are greater at age 53 (2011). This finding suggests that age-related declines in functional limitations are likely to be gender-specific. Although less research has been done on sex differences in age-related declines in physical functioning, there is some evidence that the rates of decline in physical functioning are higher among men than among women (Oksuzyan et al. 2010c).

There is also some debate about a possible sex-specific bias in some of the items used to measure IADL. Especially in the older cohorts, activities like cooking or shopping are more likely to be done by women than by men. As sex differences have been found in studies that looked at both self-reported and observed disabilities (Merrill et al. 1997), it is possible that the female disadvantage in functional limitations is independent of how these limitations are measured.

There are relatively few empirical studies that have compared gender differences in the prevalence of functional limitations across countries. Cross-country comparisons of these activities are complicated by cultural differences, such as differences in 
typical living arrangements; differences in the availability of community services; and differences in the division of labor by gender. These factors and others could influence responses to IADL items. However, Nikula et al. showed that the differences in the dependence on IADL items (preparing meals, shopping, and doing housework) by gender, age, and occupation were similar in five EU countries (Finland, Italy, the Netherlands, Spain and Sweden); and that responses to these items are therefore comparable across different countries (2003). Existing international comparisons have shown that women tend to have more functional limitations than men of the same age, although the magnitude of these sex differences varied across countries and across the types of activities analyzed. Oksuzyan et al. found a pronounced female disadvantage in ADL in Denmark, Japan, and the United States among people aged 85 and older, even though the size of the sex difference varied across these three study populations at younger ages (2010b). Furthermore, based on three large-scale population-based surveys in the EU countries, in the UK, and in the USA, Crimmins et al. found large sex differences in IADL difficulties, but similar levels of ADL disability by gender among people aged 80 and older (2011).

\section{Sex Differences in Health-Related Quality of Life}

Health-related quality of life (HRQOL) is an indicator that is highly sensitive to differences between individuals, even in subpopulations with the same objective health profile (i.e., individuals who have been diagnosed with the same disease). This is largely because this indicator is usually derived from the compilation of information from a set of items that reflect different aspects of how an individual feels as a consequence of his/her health status (e.g.: "Does pain interfere in your daily life?" "How often do you feel calm, or full of energy?"). Different tools have been developed to measure HRQOL based on the set of items used (e.g., SF36, SF20, SF12, 15D, the Nottingham Health Profile) and the wording of questions. Since these scales are often used to monitor patient health outcomes, we provide a few examples of epidemiological studies that have assessed sex differences in HRQOL among individuals with the most prevalent diseases mentioned in the sex differences in morbidity section within this chapter: namely, CVD and cancer.

In a study of stroke survivors in Japan, HRQOL was found to be higher among men than among women because women had a higher prevalence of ADL limitations and depression (Kuroda et al. 2006). Similarly, an examination of MI survivors in Spain showed that men had higher HRQOL levels than women. This study also found that the evolution of HRQOL scores from the third to the sixth month after experiencing the attack followed a sex-specific pattern: men showed greater improvements in most dimensions of physical and social functioning, while women improved in social functioning and in only few physical dimensions (Dueñas et al. 2011). Moreover, female cancer patients (colorectal and breast cancer) have been found to have lower HRQOL levels than their male counterparts (colorectal and prostate cancer) (LeMasters et al. 2013). 
The high degree of sensitivity of HRQOL to small differences enables us to use this indicator to explore health gender gaps in younger populations (i.e., children and teenagers), and thus in populations among whom health inequalities tend to be smaller than among adults. Several studies that utilized the "Kidscreen 52" questionnaire found that the gender differences in HRQOL are small among children prior to adolescence, but that adolescent girls tend to report worse levels of HRQOL than their male counterparts (Bisegger et al. 2005; Erhart et al. 2009). Most of the explanations for the emergence of these gender differences in HRQOL in adolescence refer to biological factors (e.g., that puberty is physically harder for girls), psychological factors (e.g., that girls cope with problems internally whereas boys do so externally), and social factors (e.g., that the social demands made on girls are harder to meet than those made on boys).

\section{Explanations for Sex Differences in Health and Mortality}

The most widely cited explanations for gender differences in health and survival can be classified into three general groups: biological endowments, which include hormonal and genetic factors; factors associated with lifestyle behaviors; and gender inequalities in social profiles.

\section{Hormonal Explanations}

\section{Effects of Estrogen}

A variety of studies have shown that premenopausal women have substantially lower rates of $\mathrm{CHD}$, hypertensive and cerebrovascular diseases, and related mortality than men of the same age (Lerner and Kannel 1986; Appelros et al. 2009; Sandberg and Ji 2012). After menopause, sex differences in CVD become smaller, and continue to decline as men and women age. These trends suggest that estrogen plays a central role in the sex differences in CVD (Waldron 1983; Vaccarino et al. 2010). Some studies that have examined the indirect effects of female hormones have found that estrogen has positive effects on lipoprotein profiles by decreasing total cholesterol and LDL cholesterol levels and increasing HDL cholesterol levels (Knopp et al. 1994; Miller et al. 1995). The direct effects of estrogen have been mainly attributed to two estrogen receptor subtypes, ERa and ERb, which are located in vascular endothelial and myocardial cells; as well as to a recently discovered third membrane-bound estrogen receptor, the G-protein-coupled estrogen receptor (GPR30) (Babiker et al. 2002; Mendelsohn and Karas 2005; Prossnitz and Maggiolini 2009). The existing literature has provided compelling evidence that estrogen has a range of anti-inflammatory and vasoprotective effects, including improving coronary and peripheral endothelial function; reducing ischemia, 
reperfusion injury, and inflammatory markers; and attenuating cardiac hypertrophy (Babiker et al. 2002; Wise et al. 2005; Xing et al. 2009; Yang and Reckelhoff 2011).

Research has suggested that deficient levels of endogenous estrogen due to natural or surgical menopause are associated with elevated risks of CVD morbidity and mortality (Oliver and Boyd 1959; Bairey et al. 2003; Rivera et al. 2009). However, observational studies and randomized clinical trials that extensively examined the effects of hormone replacement therapy (HRT) on CVD risk in postmenopausal women yielded conflicting results. Some studies found that HRT reduced the risks of CVD events and mortality in postmenopausal women (Bush 1990; Stampfer and Colditz 1991; Grady et al. 1992; Wise et al. 2005); whereas two major randomized clinical trials, the Women's Health Initiative and Heart and Estrogen/Progestin Replacement Study, indicated that the overall health risks associated with HRT are greater than the health benefits of estrogen plus progestin treatment among healthy postmenopausal women with an intact uterus, as well as among women with documented CHD (Grady et al. 2002; Rossouw et al. 2002; Chlebowski et al. 2003; Heiss et al. 2008).

\section{Effects of Testosterone}

The evidence regarding the effects of endogenous testosterone on men's health has been mixed (Alexandersen et al. 1996; Vitale et al. 2009; Araujo et al. 2011; Ruige et al. 2011; Schooling 2015). Although some studies have reported negative associations between low testosterone levels and the risk of ischemic stroke and of all-cause, CVD, and cancer mortality; the question of whether these associations are causal, or whether testosterone is an important biomarker of overall male health, has yet to be fully investigated (Haring et al. 2010; Holmegard et al. 2016).

The existing findings concerning the health benefits of testosterone replacement therapy (TRT) have also been controversial (Haddad et al. 2007; Xu et al. 2013; Kelly and Jones 2014). Review studies have suggested that the most frequently observed health benefits of TRT include improvements in sexual function, mood and quality of life, muscle strength, and cognitive function; and increased bone mineral density (Nieschlag et al. 2004; Bassil et al. 2009; Fernández-Balsells et al. 2010). These studies have, however, also indicated that TRT may increase the risk of prostate and breast cancers, liver toxicity and tumors, testicular atrophy, infertility, gynecomastia, erythrocytosis, and skin diseases; may worsen benign prostatic hypertrophy; and could exacerbate sleep apnea. At present, however, there is no compelling evidence that TRT has adverse effects on prostate and CVD outcomes, and the long-term effects of TRT on the incidence of fractures and other health outcomes are under-investigated due to a lack of studies with a sufficiently long follow-up period. 


\section{Effects of Sex Hormones on the Immune System}

The existing research has pointed toward a female advantage in immune protection, mainly due to the immunosuppressive effects of progesterone and testosterone and the immunoenhancing effects of estrogens (Bouman et al. 2005; Pennell et al. 2012; Giefing-Kröll et al. 2015). The incidences of many bacterial, viral, parasitic, and fungal infectious diseases (e.g., leptospirosis, brucellosis, rabies, leishmaniasis, pulmonary tuberculosis, hepatitis A, meningococcal and pneumococcal infections, and seasonal influenza) were found to be substantially higher, and some infectious diseases were shown to be more severe in men than in premenopausal women (Giefing-Kröll et al. 2015). Studies have found that autoimmune diseases are more common and that immune responses to vaccinations are often stronger in women than in men (Whitacre 2001; Giefing-Kröll et al. 2015). These findings led researchers to conclude that low levels of immunocompetence among men contributes to sex differences in mortality (Owens 2002). Although the proportion of deaths from infectious diseases in overall mortality is very small in developed countries, non-communicable diseases remain major causes of death in low-income countries (MacDonald et al. 2006). Elevated inflammatory markers were found to be associated with worse physical performance and cognition, chronic diseases, disability, and mortality (Danesh et al. 1998; Harris et al. 1999; Yaffe et al. 2003; Il'yasova et al. 2005; Schaap et al. 2009; Kaptoge et al. 2010; Singh and Newman 2011). Although substantial progress has been made in this research field, the mechanisms through which sex hormones affect both non-specific (innate) and specific (adaptive) immune responses and responses to vaccines, and the ways in which HRT can modify alterations in the immune system in humans, have not yet been fully elucidated.

\section{Genetic Explanations}

As the result of extensive mammalian evolution, in the human organism there are more than 1100 genes on the $\mathrm{X}$ chromosome, which are involved in various physiological processes; and fewer than 100 genes on the $\mathrm{Y}$ chromosome, which determine male sex (Ross et al. 2005). The presence of two copies of the $X$ chromosome in women explains the female advantage in the risk of contracting certain X-linked diseases, such as hemophilia A, Duchenne muscular dystrophy, $\mathrm{X}$-linked agammaglobulinemia; as well as the female advantage related to the modification of gene expression on the paternal or the maternal $\mathrm{X}$ chromosome. To equalize the expression of $\mathrm{X}$ gene dosage in women and men, one copy of $\mathrm{X}$ chromosomes is silenced ( $\mathrm{X}$ inactivation), and this process occurs randomly with regard to the parental origin of the X chromosome (Lyon 1962; Migeon 1994). The process of random $\mathrm{X}$ inactivation creates so-called cellular mosaicism in womeni.e., half of a woman's cells contain active paternal $\mathrm{X}$ chromosome, while the other half contain active maternal X chromosome - that underlies this female biological advantage (Migeon 2007). Such a deleterious mutation of or variation in a normally 
functioning gene on the maternal X-chromosome will be expressed in all cells in men, but will be expressed in only half of the cells in women, as the paternal $\mathrm{X}$ chromosome is likely to be intact, and is likely to ameliorate the harmful effects of the gene mutation. In addition, the cellular mosaicism in women contributes to physiological diversity, which can be advantageous when encountering new immune challenges (Spolarics 2007; Morris and Harrison 2009). However, X chromosome abnormalities - e.g., extreme inactivation skewing and inactive chromosome reactivation-may also be disadvantageous for females, and may underlie the female preponderance in autoimmunity (Libert et al. 2010).

\section{Lifestyle Explanations}

Gender differences in risk-taking behaviors have been used to define, among other factors, the constructs of masculinity and femininity, with masculinity being linked to greater social acceptance of risky behaviors, and femininity being linked to higher levels of social control (De Visser and Smith 2007). These two concepts were proposed to explain why men and women behave differently based on social norms, and how these behaviors may influence health (Courtenay 2000; Lyons 2009). The greater social acceptance of men engaging in risky behaviors contributes to sex differences in health by eroding the health status of men, whereas the social control of women's behavior may protect women's health (Denton et al. 2004).

\section{Tobacco and Alcohol Consumption}

Tobacco is still known as "the single largest preventable cause of death and disease in the United States" (CDC 2012). This is the case in EU countries as well, where smoking has been described as "the most important cause of gender differences in mortality across Europe" (McCartney et al. 2011). Levels of alcohol consumption are more heterogeneous across countries (La Vecchia et al. 2014). The contribution of alcohol consumption to mortality is between 3 and $8 \%$ in EU countries (Rehm et al. 2009), and is up to $10 \%$ at working ages in the United States (Stahre et al. 2014).

There is compelling evidence that there are gender differences in both the prevalence and the levels of alcohol consumption. Across all western countries, more men than women consume tobacco and alcohol (Costanza et al. 2006; Robinson and Harris 2011), and the consumption of these substances has greater effects on health and survival among men than among women at the aggregated level (Mucha et al. 2006; Stahre et al. 2014). Men have been shown to have a greater propensity than women to engage in risky behaviors, and the link between risky behaviors and the social concept of masculinity appears to underlie the sex differences in the consumption of both alcohol and tobacco. For instance, in a qualitative study of young men in London alcohol consumption was described as a marker of masculinity (De Visser and Smith 2007). As gender-based double 
standards regarding alcohol consumption persist even among men and women who have similar consumption levels, there is clear evidence of a link between drinking and masculinity (De Visser and McDonnell 2012).

However, in recent generations in developed countries the gender gap in smoking (Pampel 2006) and alcohol consumption (Bloomfield et al. 2006; De Visser and McDonnell 2012) appears to have decreased, or even reversed. This gap has decreased due to both a reduction in male consumption and an increase in female consumption of both substances. The main explanations for these trends are the empowerment of women and the decline in gender inequality in western societies (Hitchman and Fong 2011). Accordingly, a number of studies have pointed to the urgent need to include women in the target populations of campaigns aimed at discouraging the consumption of these substances (Amos et al. 2011).

\section{Diet}

The effects of dietary patterns on health and survival have been extensively studied. The consumption of higher quantities of vegetables and fruits and of smaller amounts of red meat - which are typical features of the Mediterranean diet-have been shown to be strongly correlated with having better health and a longer life (Haveman-Nies et al. 2002; Knoops et al. 2004; Kourlaba and Panagiotakos 2009).

The literature that looked at the sex differences in diet has suggested that women tend to have healthier eating habits than men. Women are more likely than men at almost all ages to report eating more vegetables and fruits and fewer fatty and high-carbohydrate food products (Bere et al. 2008; Dehghan et al. 2011; Kiefer et al. 2013). One of the main explanations for why women are more likely than men to follow the dietary guidelines is that women tend to be concerned about the possible disadvantages of having an unhealthy diet, including gaining weight. Meanwhile, men tend to report that they do not care about their diet, and that they have little knowledge of what a healthy diet would be (Courtenay 2000; Gough and Conner 2006). Indeed, the gender gap in food preferences appears to be attenuated after nutrition knowledge is controlled for (Baker and Wardle 2003).

Among the social-oriented explanations for this gap are that women generally know more than men about healthy eating because they are more involved in activities like shopping or cooking (Wardle et al. 2004). Thus, women are more likely than men to be exposed to information about healthy food choices. A qualitative study showed that most men delegated the responsibility for making food choices to their female partner (Newcombe et al. 2012). But this is not the only aspect of the male approach to diet. A review of 44 UK newspaper articles on the topic of men and diet concluded that men who follow a healthy diet and express concerns about healthy eating are judged as being less masculine, whereas women are seen as being experts in healthy eating (Gough and Conner 2006). These social attitudes may partially explain why men are more reluctant than women to learn about the features of a healthy diet (Wardle et al. 2004). 


\section{Physical Activity}

Epidemiological studies have provided consistent evidence regarding the relationship between physical activity and health. These studies have shown that regular activity can contribute to the prevention of certain chronic diseases (Warburton et al. 2006), the maintenance of mental well-being (Penedo and Dahn 2005), and improvements in survival among people of all ages (Löllgen et al. 2009). Current public health policies rate physical activity together with diet as the most critical issues in health promotion, especially in light of the increasing prevalence of obesity and diabetes in many high-income countries.

Gender differences in attitudes toward physical activity and sports typically appear at early ages. The number of boys enrolled in sport clubs that involve high-intensity exercise (e.g., football, basketball, bicycling) is clearly higher than the number of girls (Vilhjalmsson and Kristjansdottir 2003; Borraccino et al. 2009). This gender gap in involvement in sports translates into sex differences in the number of hours per week individuals spend doing exercise not only in childhood, but also in adulthood (Kjønniksen et al. 2009). Boys and girls also appear to have different motivations for enrolling in a youth sport club: boys tend to report engaging in physical activities for the sake of competition and in order to demonstrate their abilities (male-oriented features); while girls tend to report exercising for health reasons, for social reasons, or to improve their appearance (female-oriented features) (Vilhjalmsson and Kristjansdottir 2003).

A study that compared exercise habits in 20 countries found that young men are more likely than their female counterparts to report having high levels of physical activity (Bauman et al. 2009). However, while men are more likely than women to be active at adult ages, women are less likely than men to reduce their levels of physical activity as they age, and are thus more likely to maintain their exercise levels throughout their lives (Sjöström et al. 2006; Bauman et al. 2009).

\section{Social Explanations}

\section{Social Determinants of Health}

The factors used to define an individual's social position are commonly referred to as the social determinants of health, and are defined as follows: "The social determinants of health are the conditions in which people are born, grow, work, live, and age, and the wider set of forces and systems shaping the conditions of daily life" (WHO 2016). The social determinants of health are also related to an individual's resilience when faced with a stressful life event, such as a period of unemployment or a separation or divorce. Although sex differences in social profiles have been extensively investigated, there is little research on the implications of social profiles on the gender gap in health and mortality. 
The most extensively studied social determinants of health are related to the socioeconomic status of individuals (education, income, occupation, etc.) (Raphael 2004; Marmot 2005). However, other social factors such as the family, which is described in the chapter by Hank and Steinbach in this book, may also be associated with health inequities. Evidence of such links has led researchers to propose various conceptual models for integrating a majority of these factors. The "Rainbow Model," which was proposed by Dahlgren and Whitehead, stands out from the others because of its simple but holistic approach (1991). The authors have argued that together with the demographic profile and constitutional factors (such as genetic features) of each individual, there are three levels of determinants of health: individual factors like lifestyle, which have already been introduced in this chapter; intermediate factors like social and community networks, including family and living and working conditions; and macro factors, such as the general socioeconomic, cultural, and environmental conditions into which gender inequity levels could be placed (also see Oláh, Kotowska, and Richter in this volume). In this chapter, we mainly focus on gender differences based on the social determinants of health that are of a socioeconomic nature.

\section{Education}

A large body of existing literature has emphasized the importance of education as a social determinant of health. Population-based studies have consistently shown that education is related to both health and mortality: i.e., the higher the educational status of an individual is, the better he or she is likely to perform on health measures such as self-perceived health, cancer, CVD, and other chronic diseases, and mortality (Von Dem Knesebeck et al. 2006; Albano et al. 2007; Conti et al. 2010). There are two main explanations for the association between education and health: first, better educated people are more likely than less educated people to have access to the knowledge needed to maintain a healthy lifestyle (as was previously described); and, second, education is a socioeconomic indicator that reflects people's economic capacity to gain the access to health-protective resources (e.g., better health care, higher quality food). Although the association between education and health is universal, the magnitude of this link is not homogeneous across all the countries. For instance, across EU countries social inequalities in self-perceived health and functional limitations have been shown to be relatively small in Norway, Sweden, the United Kingdom, and Austria; but relatively large in Hungary, Poland, and Portugal (Von Dem Knesebeck et al. 2006). The sources of these differences are still not completely understood.

As is the case with other measures of socioeconomic status, historical gaps between men and women have been observed in different dimensions of education, like educational attainment or even access to education at different levels, from primary school to university. In Europe, families traditionally encouraged more of their sons than of their daughters to attain high levels of education. Thus, until the 1960s men had higher rates of school and university attendance than women (European Commission 2009). Today, however, this gender gap has been closed 
and even reversed in western countries (Gakidou et al. 2010). A period of social development during the second half of the 20th century in Europe contributed to the spread of school access in most nations, especially for women. Currently, women exceed men with regard to access to and success at higher educational levels (van Bavel 2011). However, a study that compared gender differences in education across 37 EU countries showed that these gaps are country-specific, and that men's and women's educational attainment levels are influenced by different factors (McDaniel 2011). The study indicated that family background and country-specific fertility patterns and labor market conditions have considerable influence on the gender gaps in education. For example, men who grew up without a father present or with economic deprivation were found to be less likely than their more advantaged counterparts to complete university. In addition, a high level of general fertility in a country was shown to increase the probability of completing tertiary education for both men and women, whereby the probability was greater for women than for men if the level of fertility was low. The study also found that the labor market influences men's education more than women's education, as men were shown to be less likely to complete university in countries with more job opportunities in industry or with high unemployment rates.

The reversal of the gender gap in education has substantially influenced not just female survival rates, but child mortality rates. As women gained more knowledge about healthy lifestyles, the health of both mothers and their children from pregnancy to the first years of life improved (Cleland 2010; Gakidou et al. 2010). The outcomes of this process of female educational expansion appear to suggest that the relationships between education and health and mortality differ by gender. Recently, a study of US data showed that having a higher education is associated with improvements in survival, but not in health, in the male population; whereas the opposite pattern can be observed in the female population (Ross et al. 2012). These findings suggest that education may contribute to the reduction in the male-female health-survival paradox by acting in each of the dimensions in which men and women seem to be less favored. In the European context, a study conducted by Cacciani et al. for the city of Rome found that male mortality is more sensitive than female mortality to educational differences (Cacciani et al. 2015). However, other studies have found similar effects of education on mortality among men and women (Zajacova 2006), and variations in these effects by age (Pongiglione and Sabater 2014). An examination of $14 \mathrm{EU}$ countries showed that educational inequalities in self-perceived health were relatively large among young and middle-aged men, but that education-related levels of self-perceived health tend to converge in both genders at older ages (Pongiglione and Sabater 2014).

\section{Employment}

While researchers have generally shown as much interest in investigating employment status as a proxy for an individual's socioeconomic status as they have 
in examining the role of education, some differences between these indictors have been identified: i.e., education is seen as a proxy for both socioeconomic status and knowledge about healthy lifestyles, whereas employment appears to be mainly related to socioeconomic status. While it is well known that employment, which is an indicator of access to a certain salary, is positively related to health, this relationship may also be a result of the selection of healthier individuals into the labor force (Smith et al. 1998; Wilkinson and Marmot 2003). Similarly, the literature has shown that within the employed sub-population, the higher a person's salary is, the better his or her health status is likely to be (Johnson 2009; Hawkins et al. 2012). It is not only the individual's own socioeconomic status that determines salary, but also parental social class influences the probability that the person will have a low or high salary (Smith 1996; Deaton 2008). Some researchers have, however, pointed out that using salary as an indicator of socioeconomic status can be problematic due to the relatively high non-response rate on this item in surveys, and the low degree of reliability of the responses (Galobardes et al. 2006).

A variety of studies have demonstrated that unemployment is related to adverse mental and physical health, unfavorable lifestyles, and increased mortality risk (McKee-Ryan et al. 2005; Cohen et al. 2007; Virtanen et al. 2008; Roelfs et al. 2011; Leist et al. 2013). Although a growing body of research has found that unemployment has differential effects on health in men and women, the results of these studies have been inconsistent. While some studies have found that the mental health of men and women is equally affected by unemployment (Hammarström and Janlert 1997; Bjarnason and Sigurdardottir 2003), other studies have shown that self-rated health is more likely to worsen among women than among men after becoming unemployed (Giatti et al. 2008; Reine et al. 2013). Contradictory results have also been found for the likelihood of using more alcohol and tobacco after becoming unemployed. While some studies have uncovered a relationship between unemployment and increased alcohol consumption and smoking in unemployed men only (Reine et al. 2013), a Swedish study found that this association was attenuated in women after controlling for having children (Janlert and Hammarstrom 1992; De Vogli and Santinello 2005; Bolton and Rodriguez 2009), and yet another study found that young women smoked more after becoming unemployed (Hammarström and Janlert 2003). An international comparison has shown that gender differences in the effects of unemployment on health differ in Ireland and Sweden. This finding suggests that the positions and the roles of men and women in the labor market and in the family are important factors explaining the negative consequences of the negative consequences of unemployment on health (Strandh et al. 2013).

Unlike education, a clear gender gap favoring men with respect to both employment and salary level continues to exist in most industrialized countries, albeit with different magnitudes (Peracchi 2001). Some observers have pointed to the uneven evolution of the gender gaps in education and labor market participation as a sign that the gender revolution is incomplete (McDonald 2000). The magnitude of the gender differences in labor market participation levels vary substantially across EU countries (Eurostat 2016). In 2014, the gap between the male and the 
female employment rates at ages 20-64 was $10.5 \%$ units for the whole EU-27, with Malta having the largest (25.4\% units) and Finland having the smallest (1.5\% units) gap. The mostly analyzed factor that explore ways to reduce this gap is the type of welfare state. Mandel and Semyonov (2006) showed that countries with a more family-oriented welfare state or with a large public service sector have relatively high female labor force participation levels, and concluded that "the impact of the state on women's employment opportunities is multidimensional and can be attributed to a series of factors, especially to the roles of the state as a legislator, as a provider of social services, and as an employer." The authors emphasized that the more women are integrated into the paid economy of a country, the higher the level of female empowerment is in the society. However, the integration of women into the labor market must be accompanied by a reduction in gender inequalities in individual wages (Weichselbaumer and Winter-Ebmer 2005; Arulampalam et al. 2007), and in the vertical segregation of the labor market to further reduce gender inequalities in both employment and salary level.

\section{Conclusions and Future Research Directions}

This review has shown that there is a growing body of research literature that has examined sex differences in health and mortality. Most existing studies on sex differences in mortality have focused on high-income countries. Meanwhile, relatively little research on this issue has been conducted in middle- and low-income countries. As more high-quality data become available, researchers will be able to investigate whether sex differences in mortality in these countries follow patterns similar to those that have been observed in high-income countries; and to examine how the magnitude of sex disparities in a given country is related to its economic development level. There is a growing need for research that summarizes recent trends in sex differences in mortality by causes of death and in specific geographic regions, such as the eastern and central EU countries, the Baltic states, Transcaucasia, and the other former Soviet republics; as well as in the most populous countries of the world, India and China.

Since health is a multidimensional concept, is not surprising that there is an increasing amount of evidence suggesting that gender differences in health vary in their directions and magnitudes. The selection of a health measure in a research study often depends on data availability. Thus, we need to gain a better understanding of how subjective and objective measures are interrelated, and how predictive these measures are of mortality at both the individual and the population levels. Solé-Auró and Crimmins showed that the best-performing countries with respect to life expectancy are not the countries that report the highest levels of health (Solé-Auró and Crimmins 2013). A similar analysis that looks at sex differences in health and in mortality may show that patterns are mixed, but it may also suggest there are some individual- and macro-level factors that affect health in women and survival in men differently. 
In the epidemiological, social, and demographic studies that have so far been conducted, investigations of social disparities in health and mortality have yielded the most consistent evidence. However, less is known about the magnitude of gender differences in health and mortality across educational and socioeconomic status groups, and how changes in these gaps over the life course contribute to explanations of sex differences in mortality. Although a plethora of research has investigated the effects of marriage and reproduction on individual health and mortality risks, the number of studies that have focused on sex differences in these outcomes by childbearing status and marital status is limited.

Previous research has indicated that some migrant groups are healtheir and live longer than the host country population, the so called "healthy migrant effect" (Razum and Twardella 2002; Hedlund et al. 2008; Hill et al. 2012). It has been suggested that the health advantages of immigrants diminish at older ages and among the second generation (Sundquist and Winkleby 1999; De Maio 2010); and that these advantages vary substantially by cause of death, country of birth/origin (Stirbu et al. 2006; Wild et al. 2007; Boulogne et al. 2012), and the health measure used (Sundquist and Johansson 1997; Pudaric et al. 2003; Llacer et al. 2007; Nielsen and Krasnik 2010). While there is a large body of research on health and mortality by migration background, there is a dearth of research examining the health and the mortality of migrants through a gender lens.

It is also important that we continue an existing line of research that has been investigating the role of biological factors in explaining sex differences in health and mortality. The emotional stress associated with spousal loss has been found to negatively affect immune defenses at older ages (Khanfer et al. 2011). Considering the female advantage in immunity, it is important to investigate whether changes in immune responses due to spousal bereavement are sex-specific, and whether these differences might partially explain excess mortality and worse health outcomes after widowhood among men than among women. This issue is also an example of how biological (immune defenses) and social factors (change in marital status) may modify sex differences in health, and of how the use of multidisciplinary approaches could provide additional explanations for sex differences in health and mortality.

\section{References}

Albano, J. D., Ward, E., Jemal, A., Anderson, R., Cokkinides, V. E., Murray, T., et al. (2007). Cancer mortality in the United States by education level and race. Journal of the National Cancer Institute, 99(18), 1384-1394.

Alexandersen, P., Haarbo, J., et al. (1996). The relationship of natural androgens to coronary heart disease in males: A review. Atherosclerosis, 125(1), 1-13.

Alfaro-Acha, A., Snih, S. A., et al. (2006). Handgrip strength and cognitive decline in older Mexican Americans. The Journals of Gerontology Series A: Biological Sciences and Medical Sciences, 61(8), 859-865.

Alonso-Nanclares, L., Gonzalez-Soriano, J., et al. (2008). Gender differences in human cortical synaptic density. Proceedings of the National Academy of Sciences, 105(38), 14615-14619. 
Aluja-Fabregat, A., Colom, R., et al. (2000). Sex differences in general intelligence defined as $\mathrm{g}$ among young adolescents. Personality and Individual Differences, 28(4), 813-820.

Amos, A., Greaves, L., Nichter, M., \& Bloch, M. (2011). Women and tobacco: A call for including gender in tobacco control research, policy and practice. Tobacco Control, 21, 236-243.

Anand, S. S., Xie, C. C., et al. (2005). Differences in the management and prognosis of women and men who suffer from acute coronary syndromes. Journal of the American College of Cardiology, 46(10), 1845-1851.

Andersen, K. K., Andersen, Z. J., et al. (2011). Predictors of early and late case-fatality in a nationwide Danish study of 26818 patients with first-ever ischemic stroke. Stroke, 42(10), 2806-2812.

Angst, J., Gamma, A., et al. (2002). Toward validation of atypical depression in the community: Results of the Zurich cohort study. Journal of Affective Disorders, 72(2), 125-138.

Ankney, D. C. (1992). Sex differences in relative brain size: The mismeasure of woman, too? Intelligence, 16(3-4), 329-336.

Appelros, P., Stegmayr, B., et al. (2009). Sex differences in stroke epidemiology: A systematic review. Stroke, 40(4), 1082-1090.

Appelros, P., Stegmayr, B., et al. (2010). A review on sex differences in stroke treatment and outcome. Acta Neurologica Scandinavica, 121(6), 359-369.

Araujo, A. B., Dixon, J. M., et al. (2011). Endogenous testosterone and mortality in men: A systematic review and meta-analysis. The Journal of Clinical Endocrinology \& Metabolism, 96(10), 3007-3019.

Arulampalam, W., Booth, A. L., \& Bryan, M. L. (2007). Is there a glass ceiling over Europe? Exploring the gender pay gap across the wage distribution. ILR Review, 60(2), 163-186.

Ayala, C., Croft, J. B., et al. (2002). Sex differences in US mortality rates for stroke and stroke subtypes by race/ethnicity and age, 1995-1998. Stroke, 33(5), 1197-1201.

Babiker, F. A., De Windt, L. J., et al. (2002). Estrogenic hormone action in the heart: Regulatory network and function. Cardiovascular Research, 53(3), 709-719.

Bairey, N. C. M., Johnson, B. D., et al. (2003). Hypoestrogenemia of hypothalamic origin and coronary artery disease in premenopausal women: A report from the NHLBI-sponsored WISE study. Journal of the American College of Cardiology, 41(3), 413-419.

Baker, D. P., \& Jones, D. P. (1993). Creating gender equality: Cross-national gender stratification and mathematical performance. Sociology of Education, 66(2), 91-103.

Baker, A. H., \& Wardle, J. (2003). Sex differences in fruit and vegetable intake in older adults. Appetite, 40(3), 269-275.

Barefoot, J. C., Mortensen, E. L., et al. (2001). A longitudinal study of gender differences in depressive symptoms from age 50 to 80. Psychology and Aging, 16(2), 342-345.

Barford, A., Dorling, D., et al. (2006). Life expectancy: Women now on top everywhere. BMJ, 332(7545), 808.

Barnes, L. L., Wilson, R. S., et al. (2003). Gender, cognitive decline, and risk of AD in older persons. Neurology, 60(11), 1777-1781.

Barrett, K. M., Brott, T. G., et al. (2007). Sex differences in stroke severity, symptoms, and Deficits after first-ever ischemic stroke. Journal of Stroke and Cerebrovascular Diseases, 16(1), 34-39.

Bassil, N., Alkaade, S., et al. (2009). The benefits and risks of testosterone replacement therapy: A review. Therapeutics and Clinical Risk Management, 5, 427-448.

Bauman, A., Bull, F., Chey, T., Craig, C. L., Ainsworth, B. E., Sallis, J. F., et al. (2009). The international prevalence study on physical activity: Results from 20 countries. International Journal of Behavioral Nutrition and Physical Activity, 6(1), 6-21.

Bebbington, P. E., Dunn, G., et al. (1998). The influence of age and sex on the prevalence of depressive conditions: Report from the National Survey of Psychiatric Morbidity. Psychological Medicine, 28(1), 9-19.

Beltrán-Sánchez, H., Finch, C. E., et al. (2015). Twentieth century surge of excess adult male mortality. Proceedings of the National Academy of Sciences, 112(29), 8993-8998. 
Benyamini, Y., Leventhal, E. A., \& Leventhal, H. (2000). Gender differences in processing information for making self-assessments of health. Psychosomatic Medicine, 62(3), 354-364.

Bere, E., Brug, J., \& Klepp, K. I. (2008). Why do boys eat less fruit and vegetables than girls? Public health nutrition, 11(3), 321-325.

Berrino, F., De Angelis, R., et al. (2007). Survival for eight major cancers and all cancers combined for European adults diagnosed in 1995-99: Results of the EUROCARE-4 study. The Lancet Oncology, 8(9), 773-783.

Bisegger, C., Cloetta, B., von Bisegger, U., Abel, T., \& Ravens-Sieberer, U. (2005). Health-related quality of life: Gender differences in childhood and adolescence. Sozial-und Präventivmedizin, 50(5), 281-291.

Bjarnason, T., \& Sigurdardottir, T. J. (2003). Psychological distress during unemployment and beyond: Social support and material deprivation among youth in six northern European countries. Social Science and Medicine, 56(5), 973-985.

Bjerkeset, O., Romundstad, P., et al. (2008). Gender differences in the association of mixed anxiety and depression with suicide. The British Journal of Psychiatry, 192(6), 474-475.

Blomkalns, A. L., Chen, A. Y., et al. (2005). Gender disparities in the diagnosis and treatment of non-ST-segment elevation acute coronary syndromes Large-scale observations from the CRUSADE (Can rapid risk stratification of unstable angina patients suppress adverse outcomes with early implementation of the American College of Cardiology/American Heart Association Guidelines) National Quality Improvement Initiative. Journal of the American College of Cardiology, 45(6), 832-837.

Bloomfield, K., Gmel, G., \& Wilsnack, S. (2006). Introduction to special issue 'Gender, culture and alcohol problems: a multi-national study'. Alcohol and Alcoholism, 41(suppl 1), i3-i7.

Bohannon, R. W., Peolsson, A., et al. (2006). Reference values for adult grip strength measured with a Jamar dynamometer: A descriptive meta-analysis. Physiotherapy, 92(1), 11-15.

Bolton, K. L., \& Rodriguez, E. (2009). Smoking, drinking and body weight after re-employment: Does unemployment experience and compensation make a difference? BMC Public Health, 9(1), 77.

Borraccino, A., Lemma, P., Iannotti, R., Zambon, A., Dalmasso, P., Lazzeri, G., et al. (2009). Socio-economic effects on meeting PA guidelines: Comparisons among 32 countries. Medicine and Science in Sports and Exercise, 41(4), 749-756.

Boulogne, R., Jougla, E., et al. (2012). Mortality differences between the foreign-born and locally-born population in France (2004-2007). Social Science and Medicine, 74(8), 12131223.

Bouman, A., Heineman, M. J., et al. (2005). Sex hormones and the immune response in humans. Human Reproduction Update, 11(4), 411-423.

Bowling, A., Bond, M., et al. (2001). Equity in access to exercise tolerance testing, coronary angiography, and coronary artery bypass grafting by age, sex and clinical indications. Heart, 85(6), 680-686.

Brådvik, L., Mattisson, C., et al. (2008). Long-term suicide risk of depression in the Lundby cohort 1947-1997-severity and gender. Acta Psychiatrica Scandinavica, 117(3), 185-191.

Burgaleta, M., Head, K., et al. (2012). Sex differences in brain volume are related to specific skills, not to general intelligence. Intelligence, 40(1), 60-68.

Bush, T. L. (1990). The epidemiology of cardiovascular disease in postmenopausal women. Annals of the New York Academy of Sciences, 592(1), 263-271.

Butler, A. A., Menant, J. C., et al. (2009). Age and gender differences in seven tests of functional mobility. Journal of NeuroEngineering and Rehabilitation, 6(1), 1-9.

Cacciani, L., Bargagli, A. M., Cesaroni, G., Forastiere, F., Agabiti, N., \& Davoli, M. (2015). Education and mortality in the Rome longitudinal study. PLOS ONE, 10(9), e0137576.

Cairney, J., \& Wade, T. J. (2002). The influence of age on gender differences in depression further population-based evidence on the relationship between menopause and the sex difference in depression. Social Psychiatry and Psychiatric Epidemiology, 37(9), 401-408.

Case, A., \& Paxson, C. (2005). Sex differences in morbidity and mortality. Demography, 42(2), 189-214. 
Cawthon, P. M., Fox, K. M., et al. (2009). Do muscle mass, muscle density, strength, and physical function similarly influence risk of hospitalization in older adults? Journal of the American Geriatrics Society, 57(8), 1411-1419.

Centers for Disease Control and Prevention (CDC). (2012). Current cigarette smoking among adults-United States, 2011. MMWR. Morbidity and mortality weekly report, 61(44), 889.

Chlebowski, R. T., Hendrix, S. L., et al. (2003). Influence of estrogen plus progestin on breast cancer and mammography in healthy postmenopausal women: The women's health initiative randomized trial. JAMA, 289(24), 3243-3253.

Cleland, J. (2010). The benefits of educating women. The Lancet, 376(9745), 933-934.

Cohen, F., Kemeny, M. E., et al. (2007). Immune function declines with unemployment and recovers after stressor termination. Psychosomatic Medicine, 69(3), 225-234.

Colom, R., Juan-Espinosa, M., et al. (2000). Negligible sex differences in general intelligence. Intelligence, 28(1), 57-68.

Conti, G., Heckman, J., \& Urzua, S. (2010). The education-health gradient. The American Economic Review, 100(2), 234-238.

Cook, M. B., Dawsey, S. M., et al. (2009). Sex disparities in cancer incidence by period and age. Cancer Epidemiology, Biomarkers and Prevention, 18(4), 1174-1182.

Cook, M. B., McGlynn, K. A., et al. (2011). Sex disparities in cancer mortality and survival. Cancer Epidemiology, Biomarkers and Prevention, 20(8), 1629-1637.

Cooper, R., Hardy, R., et al. (2011). Age and gender differences in physical capability levels from mid-life onwards: The harmonisation and meta-analysis of data from eight UK cohort studies. PLOS ONE, 6(11), e27899.

Costanza, M. C., Salamun, J., Lopez, A. D., \& Morabia, A. (2006). Gender differentials in the evolution of cigarette smoking habits in a general European adult population from 1993-2003. BMC Public Health, 6, 130.

Courtenay, W. H. (2000). Constructions of masculinity and their influence on men's well-being: A theory of gender and health. Social Science and Medicine, 50(10), 1385-1401.

Crimmins, E. M., Kim, J. K., et al. (2011). Gender differences in health: Results from SHARE, ELSA and HRS. The European Journal of Public Health, 21(1), 81-91.

Crimmins, E. M., \& Saito, Y. (2001). Trends in healthy life expectancy in the United States, 19701990: Gender, racial, and educational differences. Social Science and Medicine, 52, 1629 1641.

Crossley, M., D'Arcy, C., et al. (1997). Letter and category fluency in community-dwelling canadian seniors: A comparison of normal participants to those with dementia of the Alzheimer or vascular type. Journal of Clinical and Experimental Neuropsychology, 19(1), 52-62.

Cutler, J. A., Sorlie, P. D., et al. (2008). Trends in hypertension prevalence, awareness, treatment, and control rates in United States adults between 1988-1994 and 1999-2004. Hypertension, 52 (5), 818-827.

Dahlgren, G., \& Whitehead, M. (1991). Policies and strategies to promote social equity in health. Stockholm, Sweden.

Dahlin, J., \& Härkönen, J. (2013). Cross-national differences in the gender gap in subjective health in Europe: Does country-level gender equality matter? Social Science and Medicine, 98, 24-28.

Danesh, J., Collins, R., et al. (1998). Association of fibrinogen, c-reactive protein, albumin, or leukocyte count with coronary heart disease: Meta-analyses of prospective studies. JAMA, 279(18), 1477-1482.

de Frias, C. M., Nilsson, L.-G., et al. (2006). Sex differences in cognition are stable over a 10-year period in adulthood and old age. Aging, Neuropsychology, and Cognition, 13(3-4), 574-587.

De Maio, F. (2010). Immigration as pathogenic: A systematic review of the health of immigrants to Canada. International Journal for Equity in Health, 9(1), 27.

De Visser, R. O., \& McDonnell, E. J. (2012). 'That's OK. He's a guy': A mixed-methods study of gender double-standards for alcohol use. Psychology and Health, 27(5), 618-639.

De Visser, R. O., \& Smith, J. A. (2007). Alcohol consumption and masculine identity among young men. Psychology and Health, 22(5), 595-614. 
De Vogli, R., \& Santinello, M. (2005). Unemployment and smoking: Does psychosocial stress matter? Tobacco Control, 14(6), 389-395.

Deaton, A. (2008). Income, health and wellbeing around the world: Evidence from the gallup world poll. The Journal of Economic Perspectives: A Journal of the American Economic Association, 22(2), 53-72.

Dehghan, M., Akhtar-Danesh, N., \& Merchant, A. T. (2011). Factors associated with fruit and vegetable consumption among adults. Journal of Human Nutrition \& Dietetics, 24(2), 128-134.

Denton, M., Prus, S., \& Walters, V. (2004). Gender differences in health: A Canadian study of the psychosocial, structural and behavioural determinants of health. Social Science and Medicine, 58(12), 2585-2600.

Di Carlo, A., Lamassa, M., et al. (2003). Sex differences in the clinical presentation, resource use, and 3-month outcome of acute stroke in Europe: Data from a multicenter multinational hospital-based registry. Stroke, 34(5), 1114-1119.

Djernes, J. K. (2006). Prevalence and predictors of depression in populations of elderly: A review. Acta Psychiatrica Scandinavica, 113(5), 372-387.

Dodds, R., Denison, H. J., et al. (2012). Birth weight and muscle strength: A systematic review and meta-analysis. The Journal of Nutrition, Health \& Aging, 16(7), 609-615.

Dodds, R. M., Syddall, H. E., et al. (2014). Grip strength across the life course: Normative data from twelve British studies. PLoS ONE, 9(12), e113637.

Dorak, M. T., \& Karpuzoglu, E. (2012). Gender differences in cancer susceptibility: An inadequately addressed issue. Frontiers in Genetics, 3, 268.

Dueñas, M., Ramirez, C., Arana, R., \& Failde, I. (2011). Gender differences and determinants of health related quality of life in coronary patients: A follow-up study. BMC Cardiovascular Disorders, 11(1), 11-24.

Edgren, G., Liang, L., et al. (2012). Enigmatic sex disparities in cancer incidence. European Journal of Epidemiology, 27(3), 187-196.

Eikemo, T. A., Huisman, M., Bambra, C., \& Kunst, A. E. (2008). Health inequalities according to educational level in different welfare regimes: A comparison of 23 European countries. Sociology of Health \& Illness, 30(8), 565-582.

Else-Quest, N. M., Hyde, J. S., et al. (2010). Cross-national patterns of gender differences in mathematics: A meta-analysis. Psychological Bulletin, 136(1), 103-127.

Erhart, M., Ottova, V., et al. (2009). Measuring mental health and well-being of school-children in 15 European countries using the KIDSCREEN-10 index. International Journal of Public Health, 54(2), 160-166.

European Commission. (2009). Women in science. Luxembourg: Office for Official Publications of the European Communities.

Eurostat (2016). Equality (Age and Gender): Gender Equality: Labour Market: Employment and activity by sex and age - annual data. http://ec.europa.eu/eurostat/web/equality/data/database Accessed 15 March 2016.

Ferlay, J., Steliarova-Foucher, E., et al. (2013). Cancer incidence and mortality patterns in Europe: Estimates for 40 countries in 2012. European Journal of Cancer, 49(6), 1374-1403.

Fernández-Balsells, M. M., Murad, M. H., et al. (2010). Adverse effects of testosterone therapy in adult men: A systematic review and meta-analysis. The Journal of Clinical Endocrinology \& Metabolism, 95(6), 2560-2575.

Frederiksen, H., Hjelmborg, J., et al. (2006). Age trajectories of grip strength: Cross-sectional and longitudinal data among 8,342 Danes aged 46 to 102. Annals of Epidemiology, 16(7), 554-562.

Freedman, D. S., Otvos, J. D., et al. (2004). Sex and age differences in lipoprotein subclasses measured by nuclear magnetic resonance spectroscopy: The Framingham study. Clinical Chemistry, 50(7), 1189-1200.

Fujita, Y., Nakamura, Y., et al. (1995). Physical-strength tests and mortality among visitors to health-promotion centers in Japan. Journal of Clinical Epidemiology, 48(11), 1349-1359.

Gakidou, E., Cowling, K., Lozano, R., \& Murray, C. J. (2010). Increased educational attainment and its effect on child mortality in 175 countries between 1970 and 2009: A systematic analysis. The Lancet, 376(9745), 959-974. 
Galatius, J. S., Launbjerg, J., et al. (1996). Sex related differences in short and long term prognosis after acute myocardial infarction: 10 year follow up of 3073 patients in database of first Danish verapamil infarction trial. BMJ, 313(7050), 137-140.

Gale, C. R., Martyn, C. N., et al. (1996). Cognitive impairment and mortality in a cohort of elderly people. BMJ, 312(7031), 608-611.

Galobardes, B., Shaw, M., Lawlor, D. A., Lynch, J. W., \& Smith, G. D. (2006). Indicators of socioeconomic position (part 1). Journal of Epidemiology and Community Health, 60(1), 7-12.

Gerstorf, D., Herlitz, A., et al. (2006). Stability of sex differences in cognition in advanced old age: The role of education and attrition. The Journals of Gerontology Series B: Psychological Sciences and Social Sciences, 61(4), P245-P249.

Ghisletta, P. (2008). Application of a joint multivariate longitudinal-survival analysis to examine the terminal decline hypothesis in the Swiss interdisciplinary longitudinal study on the oldest old. Journals of Gerontology. Series B, Psychological Sciences and Social Sciences, 63(3), P185-P192.

Giampaoli, S., Ferrucci, L., et al. (1999). Hand-grip strength predicts incident disability in non-disabled older men. Age and Ageing, 28(3), 283-288.

Giatti, L., Barreto, S. M., et al. (2008). Household context and self-rated health: The effect of unemployment and informal work. Journal of Epidemiology and Community Health, 62(12), 1079-1085.

Giefing-Kröll, C., Berger, P., et al. (2015). How sex and age affect immune responses, susceptibility to infections, and response to vaccination. Aging Cell, 14(3), 309-321.

Gjonca, A., Tomassini, C., et al. (2005). Sex differences in mortality, a comparison of the United Kingdom and other developed countries. Health Statistics Quarterly, 26, 6-16.

Glei, D. A., \& Horiuchi, S. (2007). The narrowing sex differential in life expectancy in high-income populations: Effects of differences in the age pattern of mortality. Population Studies (Cambridge), 61(2), 141-159.

Go, A. S., Mozaffarian, D., et al. (2013). Heart disease and stroke statistics-2013 update: A report from the american heart association. Circulation, 127(1), e6-e245.

Gold, C. H., Malmberg, B., et al. (2002). Gender and health: A study of older unlike-sex twins. Journals of Gerontology. Series B, Psychological Sciences and Social Sciences, 57(3), S168S176.

Gough, B., \& Conner, M. T. (2006). Barriers to healthy eating amongst men: A qualitative analysis. Social Science and Medicine, 62(2), 387-395.

Grady, D., Herrington, D., et al. (2002). Cardiovascular disease outcomes during 6.8 years of hormone therapy: Heart and estrogen/progestin replacement study follow-up (hers ii). JAMA, 288(1), 49-57.

Grady, D., Rubin, S. M., et al. (1992). Hormone therapy to prevent disease and prolong life in postmenopausal women. Annals of Internal Medicine, 117(12), 1016-1037.

Grigoriadis, S., \& Erlick Robinson, G. (2007). Gender issues in depression. Annals of Clinical Psychiatry, 19(4), 247-255.

Guiso, L., Monte, F., et al. (2008). Culture, gender, and math. Science-New York Then Washington, 320(5880), 1164.

Haddad, R. M., Kennedy, C. C., et al. (2007). Testosterone and cardiovascular risk in men: A systematic review and meta-analysis of randomized placebo-controlled trials. Mayo Clinic Proceedings, 82(1), 29-39.

Halpern, D. F., Benbow, C. P., Geary, D. C., Gur, R. C., Hyde, J. S., \& Gernsbacher, M. A. (2016). The science of sex differences in science and mathematics. Psychological Science in the Public Interest, 8(1), 1-51.

Hammarström, A., \& Janlert, U. (1997). Nervous and depressive symptoms in a longitudinal study of youth unemployment-Selection or exposure? Journal of Adolescence, 20(3), 293-305.

Hammarström, A., \& Janlert, U. (2003). Unemployment-An important predictor for future smoking: A 14-year follow-up study of school leavers. Scandinavian Journal of Public Health, 31, 229-232. 
Hankin, B. L., Abramson, L. Y., et al. (1998). Development of depression from preadolescence to young adulthood: Emerging gender differences in a 10-year longitudinal study. Journal of Abnormal Psychology, 107(1), 128-140.

Haring, R., Völzke, H., et al. (2010). Low serum testosterone levels are associated with increased risk of mortality in a population-based cohort of men aged 20-79. European Heart Journal, 31, $1494-1501$.

Harris, T. B., Ferrucci, L., et al. (1999). Associations of elevated Interleukin-6 and C-reactive protein levels with mortality in the elderly. The American Journal of Medicine, 106(5), 506-512.

Haveman-Nies, A., Burema, J., Cruz, J. A. A., Osler, M., \& van Staveren, W. A. (2002). Dietary quality and lifestyle factors in relation to 10-year mortality in older Europeans: The SENECA study. American Journal of Epidemiology, 156(10), 962-968.

Hawkins, N. M., Jhund, P. S., et al. (2012). Heart failure and socioeconomic status: Accumulating evidence of inequality. European Journal of Heart Failure, 14(2), 138-146.

Hedlund, E., Pehrsson, K., et al. (2008). Country of birth and survival after a first myocardial infarction in Stockholm, Sweden. European Journal of Epidemiology, 23(5), 341-347.

Heiss, G., Wallace, R., et al. (2008). Health risks and benefits 3 years after stopping randomized treatment with estrogen and progestin. JAMA, 299(9), 1036-1045.

Herlitz, A., \& Rehnman, J. (2008). Sex differences in episodic memory. Current Directions in Psychological Science, 17(1), 52-56.

Herman, B., Greiser, E., et al. (1997). A sex difference in short-term survival after initial acute myocardial infarction. The MONICA-Bremen acute myocardial infarction register, 1985-1990. European Heart Journal, 18(6), 963-970.

Hill, T., Angel, J., et al. (2012). Does the "Healthy immigrant effect" extend to cognitive aging? In J. L. Angel, F. Torres-Gil, \& K. Markides (Eds.), Aging, health, and longevity in the mexican-origin population (pp. 19-33). US: Springer.

Hitchman, S. C., \& Fong, G. T. (2011). Gender empowerment and female-to-male smoking prevalence ratios. Bulletin of the World Health Organization, 89(3), 195-202.

HMD Human Mortality Database. University of California, Berkeley and Max Planck Institute for Demographic Research. www.mortality.org.

Holmegard, H. N., Nordestgaard, B. G., et al. (2016). Sex hormones and ischemic stroke: A prospective cohort study and meta-analyses. The Journal of Clinical Endocrinology \& Metabolism, 101(1), 69-78.

Holroyd-Leduc, J. M., Kapral, M. K., et al. (2000). Sex differences and similarities in the management and outcome of stroke patients. Stroke, 31(8), 1833-1837.

Huxley, R., Barzi, F., et al. (2006). Excess risk of fatal coronary heart disease associated with diabetes in men and women: Meta-analysis of 37 prospective cohort studies. BMJ, 332(7533), 73-78.

Hyde, J. S., \& Linn, M. C. (1988). Gender differences in verbal ability: A meta-analysis. Psychological Bulletin, 104(1), 53-69.

Hyde, J. S., Mezulis, A. H., et al. (2008). The ABCs of depression: Integrating affective, biological, and cognitive models to explain the emergence of the gender difference in depression. Psychological Review, 115(2), 291-313.

Idler, E. L. (2003). Gender differences in self-rated health, in mortality, and in the relationship between the two. Gerontologist, 43(3), 372-375.

Iezzoni, L. I., Ash, A. S., et al. (1997). Differences in procedure use, in-hospital mortality, and illness severity by gender for acute myocardial infarction patients: Are answers affected by data source and severity measure? Medical Care, 35(2), 158-171.

Il'yasova, D., Colbert, L. H., et al. (2005). Circulating levels of inflammatory markers and cancer risk in the health aging and body composition cohort. Cancer Epidemiology, Biomarkers and Prevention, 14(10), 2413-2418.

Innes, E. (1999). Handgrip strength testing: A review of the literature. Australian Occupational Therapy Journal, 46(3), 120-140.

Isaksson, R.-M., Jansson, J.-H., et al. (2011). Better long-term survival in young and middle-aged women than in men after a first myocardial infarction between 1985 and 2006. An analysis of 
8630 patients in the Northern Sweden MONICA study. BMC Cardiovascular Disorders, 11(1), $1-8$.

Janlert, U., \& Hammarstrom, A. (1992). Alcohol consumption among unemployed youths: Results from a prospective study. British Journal of Addiction, 87, 703-714.

Jaussent, I., Dauvilliers, Y., et al. (2011). Insomnia symptoms in older adults: Associated factors and gender differences. The American Journal of Geriatric Psychiatry, 19(1), 88-97.

Johnson, J. V. (2009). The growing imbalance: Class, work and health in an era of increasing inequality. In P. L. Schnall, M. Dobson, \& E. Rosskam (Eds.), Unhealthy work: Causes, consequences, cures (pp. 37-59). Amityville, NY: Baywood.

Jousilahti, P., Vartiainen, E., et al. (1999). Sex, age, cardiovascular risk factors, and coronary heart disease: A prospective follow-up study of 14786 middle-aged men and women in Finland. Circulation, 99(9), 1165-1172.

Jylhä, M. (2009). What is self-rated health and why does it predict mortality? Towards a unified conceptual model. Social Science and Medicine, 69, 307-316.

Kaptoge, S., Di Angelantonio, E., et al. (2010). C-reactive protein concentration and risk of coronary heart disease, stroke, and mortality: An individual participant meta-analysis. Lancet, 375(9709), 132-140.

Kardys, I., Vliegenthart, R., et al. (2007). The female advantage in cardiovascular disease: Do vascular beds contribute equally? American Journal of Epidemiology, 166(4), 403-412.

Keevil, V. L., Hayat, S., et al. (2013). The physical capability of community-based men and women from a British cohort: The European prospective investigation into cancer (EPIC)Norfolk study. BMC Geriatrics, 13(1), 1-11.

Kelly, D. M., \& Jones, T. H. (2014). Testosterone and cardiovascular risk in men. In Cardiovascular Issues in Endocrinology (Vol. 43).

Khanfer, R., Lord, J. M., \& Phillips, A. C. (2011). Neutrophil function and cortisol: DHEAS ratio in bereaved older adults. Brain, Behavior, and Immunity, 25(6), 1182-1186.

Kiefer, I., Rathmanner, T., \& Kunze, M. (2013). Eating and dieting differences in men and women. Journal of Men's Health and Gender, 2(2), 194-201.

Kjønniksen, L., Anderssen, Nils, \& Wold, B. (2009). Organized youth sport as a predictor of physical activity in adulthood. Scandinavian Journal of Medicine and Science in Sports, 19(5), 646-654.

Knoops, K. T. B., de Groot, L. C. P. G. M., et al. (2004). Mediterranean diet, lifestyle factors, and 10-year mortality in elderly European men and women the HALE project. The Journal of the American Medical Association, 292(12), 1433-1439.

Knopp, R. H., Zhu, X., et al. (1994). Effects of estrogens on lipoprotein metabolism and cardiovascular disease in women. Atherosclerosis, 110, S83-S91.

Kockler, M., \& Heun, R. (2002). Gender differences of depressive symptoms in depressed and nondepressed elderly persons. International Journal of Geriatric Psychiatry, 17(1), 65-72.

Koek, H. L., de Bruin, A., et al. (2006). Short-and long-term prognosis after acute myocardial infarction in men versus women. The American Journal of Cardiology, 98(8), 993-999.

Kourlaba, G., \& Panagiotakos, D. B. (2009). Dietary quality indices and human health: A review. Maturitas, 62(1), 1-8.

Kuehner, C. (2003). Gender differences in unipolar depression: An update of epidemiological findings and possible explanations. Acta Psychiatrica Scandinavica, 108(3), 163-174.

Kuroda, A., Kanda, T., \& Sakai, F. (2006). Gender differences in health-related quality of life among stroke patients. Geriatrics and Gerontology International, 6(3), 165-173.

La Vecchia, C., Bosetti, C., Bertuccio, P., Castro, C., Pelucchi, C., \& Negri, E. (2014). Trends in alcohol consumption in Europe and their impact on major alcohol-related cancers. European Journal of Cancer Prevention, 23(4), 319-322.

Lavery, L. L., Dodge, H. H., et al. (2009). Cognitive decline and mortality in a community-based cohort: The Monongahela Valley independent elders survey. Journal of the American Geriatrics Society, 57(1), 94-100.

Lawlor, D. A., Ebrahim, S., et al. (2001). Sex matters: Secular and geographical trends in sex differences in coronary heart disease mortality. BMJ, 323(7312), 541-545. 
Leist, A. K., Glymour, M. M., et al. (2013). Time away from work predicts later cognitive function: Differences by activity during leave. Annals of Epidemiology, 23(8), 455-462.

LeMasters, T., Madhavan, S., Sambamoorthi, U., \& Kurian, S. (2013). A population-based study comparing HRQoL among breast, prostate, and colorectal cancer survivors to propensity score matched controls, by cancer type, and gender. Psycho-Oncology, 22(10), 2270-2282.

Leong, D. P., Teo, K. K., et al. (2015). Prognostic value of grip strength: Findings from the Prospective Urban Rural Epidemiology (PURE) study. The Lancet, 386(9990), 266-273.

Lerner, D. J., \& Kannel, W. B. (1986). Patterns of coronary heart disease morbidity and mortality in the sexes: A 26-year follow-up of the Framingham population. American Heart Journal, $111(2), 383-390$.

Lewsey, J. D., Gillies, M., et al. (2009). Sex differences in incidence, mortality, and survival in individuals with stroke in Scotland, 1986 to 2005. Stroke, 40(4), 1038-1043.

Libert, C., Dejager, L., et al. (2010). The X chromosome in immune functions: When a chromosome makes the difference. Nature Reviews Immunology, 10(8), 594-604.

Lindahl-Jacobsen, R., Hanson, H. A., et al. (2013). The male-female health-survival paradox and sex differences in cohort life expectancy in Utah, Denmark, and Sweden 1850-1910. Annals of Epidemiology, 23(4), 161-166.

Lindahl-Jacobsen, R., Rau, R., et al. (2016). Rise, stagnation, and rise of Danish women's life expectancy. PNAS, 113, 4015-4020.

Lindberg, S. M., Hyde, J. S., et al. (2010). New trends in gender and mathematics performance: A meta-analysis. Psychological Bulletin, 136(6), 1123-1135.

Ling, C. H. Y., Taekema, D., et al. (2010). Handgrip strength and mortality in the oldest old population: The Leiden 85-plus study. Canadian Medical Association Journal, 182(5), 429-435.

Linn, M. C., \& Petersen, A. C. (1985). Emergence and characterization of sex differences in spatial ability: A meta-analysis. Child Development, 56(6), 1479-1498.

Llacer, A., Zunzunegui, M. V., et al. (2007). The contribution of a gender perspective to the understanding of migrants' health. Journal of Epidemiology and Community Health, 61(Suppl 2), ii4-10.

Löllgen, H., Böckenhoff, A., \& Knapp, G. (2009). Physical activity and all-cause mortality: An updated meta-analysis with different intensity categories. International Journal of Sports Medicine, 30(3), 213-224.

Lyon, M. F. (1962). Sex chromatin and gene action in the mammalian X-chromosome. American Journal of Human Genetics, 14(2), 135-148.

Lyons, A. C. (2009). Masculinities, femininities, behaviour and health. Social and Personality Psychology Compass, 3(4), 394-412.

MacDonald, N. E., Halperin, B., et al. (2006). Infectious disease management: Lessons from Cuba. The Canadian Journal of Infectious Diseases \& Medical Microbiology, 17(4), 217.

Macintyre, S., Hunt, K., et al. (1996). Gender differences in health: Are things really as simple as they seem? Social Science and Medicine, 42(4), 617-624.

Macintyre, K., Stewart, S., et al. (2001). Gender and survival: A population-based study of 201,114 men and women following a first acute myocardial infarction. Journal of the American College of Cardiology, 38(3), 729-735.

Madigan, F. C., \& Vance, R. B. (1957). Differential sex mortality: A research design. Social Forces, 35(3), 193-199.

Maier, H., McGue, M., et al. (2003). Cognitive impairment and survival at older ages. In Brain and longevity (pp. 131-144). Springer.

Mandel, H., \& Semyonov, M. (2006). A Welfare State Paradox: State interventions and women's employment opportunities in 22 Countries. American Journal of Sociology, 111(6), 1910-49.

Marmot, M. G. (2005). Social determinants of health inequalities. The Lancet, 365, 1099-1104.

Martikainen, P., Mäkelä, P., et al. (2014). Income differences in life expectancy: The changing contribution of harmful consumption of alcohol and smoking. Epidemiology, 25(2), 182-190.

McCartney, G., Mahmood, L., Leyland, A. H., Batty, G. D., \& Hunt, K. (2011). Contribution of smoking-related and alcohol-related deaths to the gender gap in mortality: Evidence from 30 European countries. Tobacco Control, 20(2), 166-168. 
McDaniel, A. (2011). Gender differences in university completion across Europe: The influence of family background and national context. Working paper, Institute for Social and Economic Research and Policy.

McDonald, P. (2000). Gender equity in theories of fertility transition. Population and Development Review, 26(3), 427-440.

McDougall, F. A., Kvaal, K., et al. (2007). Prevalence of depression in older people in England and wales: The MRC CFA study. Psychological Medicine, 37(12), 1787-1795.

McGee, D. L., Liao, Y., et al. (1999). Self-reported health status and mortality in a multiethnic US cohort. American Journal of Epidemiology, 149, 41-46.

McKee-Ryan, F. M., Song, Z., et al. (2005). Psychological and physical well-being during unemployment: A meta-analytic study. Journal of Applied Psychology, 90(1), 53-76.

Mendelsohn, M. E., \& Karas, R. H. (2005). Molecular and cellular basis of cardiovascular gender differences. Science, 308(5728), 1583-1587.

Merrill, S. S., Seeman, T. E., Kasl, S. V., \& Berkman, L. F. (1997). Gender differences in the comparison of self-reported disability and performance measures. The Journals of Gerontology Series A: Biological Sciences and Medical Sciences, 52(1), M19-M26.

Micheli, A., Mariotto, A., et al. (1998). The prognostic role of gender in survival of adult cancer patients. European Journal of Cancer, 34(14), 2271-2278.

Migeon, B. R. (1994). X-chromosome inactivation: Molecular mechanisms and genetic consequences. Trends in Genetics, 10(7), 230-235.

Migeon, B. R. (2007). Why females are mosaics, x-chromosome inactivation, and sex differences in disease. Gender Medicine, 4(2), 97-105.

Mijnarends, D. M., Meijers, J. M. M., et al. (2013). Validity and reliability of tools to measure muscle mass, strength, and physical performance in community-dwelling older people: A systematic review. Journal of the American Medical Directors Association, 14(3), 170-178.

Milcent, C., Dormont, B., et al. (2007). Gender differences in hospital mortality and use of percutaneous coronary intervention in acute myocardial infarction: Microsimulation analysis of the 1999 nationwide French hospitals database. Circulation, 115(7), 833-839.

Miller, D. I., \& Halpern, D. F. (2014). The new science of cognitive sex differences. Trends in Cognitive Sciences, 18(1), 37-45.

Miller, V. T., LaRosa, J., et al. (1995). Effects of estrogen or estrogen/ progestin regimens on heart disease risk factors in postmenopausal women: The postmenopausal estrogen/progestin interventions (PEPI) trial. JAMA, 273(3), 199-208.

Morris, J. A., \& Harrison, L. M. (2009). Hypothesis: Increased male mortality caused by infection is due to a decrease in heterozygous loci as a result of a single $\mathrm{X}$ chromosome. Medical Hypotheses, 72(3), 322-324.

Mucha, L., Stephenson, J., Morandi, N., \& Dirani, R. (2006). Meta-analysis of disease risk associated with smoking, by gender and intensity of smoking. Gender Medicine, 3(4), 279-291.

Murtagh, K. N., \& Hubert, H. B. (2004). Gender differences in physical disability among an elderly cohort. American Journal of Public Health, 94(8), 1406-1411.

Murray, E. T., Hardy, R., Strand, B. H., Cooper, R., Guralnik, J. M., \& Kuh, D. (2011). Gender and life course occupational social class differences in trajectories of functional limitations in midlife: Findings from the 1946 British birth cohort. The Journals of Gerontology Series A: Biological Sciences and Medical Sciences, 66(12), 1350-1359.

Newcombe, M. A., McCarthy, M. B., Cronin, J. M., \& McCarthy, S. N. (2012). Eat like a man. A social constructionist analysis of the role of food in men's lives. Appetite, 59(2), 391-398.

Newman, A. B., \& Brach, J. S. (1999). Gender gap in longevity and disability in older persons. Health, 23(2), 343-350.

Nielsen, S., Björck, L., et al. (2014). Sex-specific trends in 4-year survival in 37276 men and women with acute myocardial infarction before the age of 55 years in Sweden, 1987-2006: A register-based cohort study. British Medical Journal Open, 4(5), e004598.

Nielsen, S., \& Krasnik, A. (2010). Poorer self-perceived health among migrants and ethnic minorities versus the majority population in Europe: A systematic review. International Journal of Public Health, 55(5), 357-371. 
Nieschlag, E., Behre, H. M., et al. (2004). Testosterone replacement therapy: Current trends and future directions. Human Reproduction Update, 10(5), 409-419.

Nikula, S., Jylhä, M., Bardage, C., Deeg, D. J., Gindin, J., Minicuci, N., et al. (2003). Are IADLs comparable across countries? Sociodemographic associates of harmonized IADL measures. Aging Clinical and Experimental Research, 15(6), 451-459.

Nolen-Hoeksema, S. (2001). Gender differences in depression. Current Directions in Psychological Science, 10(5), 173-176.

Nolen-Hoeksema, S., \& Girgus, J. S. (1994). The emergence of gender differences in depression during adolescence. Psychological Bulletin, 115(3), 424-443.

Oksuzyan, A., Brønnum-Hansen, H., et al. (2010a). Gender gap in health expectancy. European Journal of Ageing, 7(4), 213-218.

Oksuzyan, A., Crimmins, E., et al. (2010b). Cross-national comparison of sex differences in health and mortality in Denmark, Japan and the US. European Journal of Epidemiology, 25(7), 471-480.

Oksuzyan, A., Juel, K., et al. (2008). Men: Good health and high mortality. Sex differences in health and aging. Aging Clinical and Experimental Research, 20(2), 91-102.

Oksuzyan, A., Maier, H., et al. (2010c). Sex differences in the level and rate of change of physical function and grip strength in the Danish 1905-cohort study. Journal of Aging and Health, 22, 589-610.

Oksuzyan, A., Shkolnikova, M., et al. (2015). Sex differences in biological markers of health in the study of stress, aging and health in Russia. PLoS ONE, 10(6), e0131691.

Oliver, M. F., \& Boyd, G. S. (1959). Effect of bilateral ovariectomy on coronary-artery disease and serum-lipid levels. The Lancet, 274(7105), 690-694.

Olsen, T. S., Andersen, Z. J., et al. (2012). Explaining poorer stroke outcomes in women: Women surviving 3 months have more severe strokes than men despite a lower 3-month case fatality. Gender Medicine, 9(3), 147-153.

Ortega, F. B., Silventoinen, K., et al. (2012). Muscular strength in male adolescents and premature death: Cohort study of one million participants. BMJ, 345, e7279.

Owens, I. P. F. (2002). Ecology and evolution: Sex differences in mortality rate. Science, 297(5589), 2008-2009.

Palacios-Cena, D., Jimenez-Garcia, R., et al. (2012). Has the prevalence of disability increased over the past decade (2000-2007) in elderly people? A Spanish population-based survey. Journal of the American Medical Directors Association, 13(2), 136-142.

Pampel, F. C. (2006). Global patterns and determinants of sex differences in smoking. International Journal of Comparative Sociology, 47(6), 466-487.

Pavlik, V. N., de Moraes, S. A., et al. (2003). Relation between cognitive function and mortality in middle-aged adults: The atherosclerosis risk in communities study. American Journal of Epidemiology, 157(4), 327-334.

Penedo, F. J., \& Dahn, J. R. (2005). Exercise and well-being: A review of mental and physical health benefits associated with physical activity. Current opinion in psychiatry, 18(2), 189-193.

Pennell, L. M., Galligan, C. L., et al. (2012). Sex affects immunity. Journal of Autoimmunity, 38(2-3), J282-J291.

Peracchi, F. (2001). Earnings inequality in international perspective. In The causes and consequences of increasing inequality (pp. 117-192).

Perna, L., Wahl, H.-W., et al. (2015). Cognitive impairment, all-cause and cause-specific mortality among non-demented older adults. Age and Ageing, 44(3), 445-451.

Petrea, R. E., Beiser, A. S., et al. (2009). Gender differences in stroke incidence and poststroke disability in the framingham heart study. Stroke, 40(4), 1032-1037.

Piccinelli, M., \& Wilkinson, G. (2000). Gender differences in depression: Critical review. The British Journal of Psychiatry, 177(6), 486-492.

Pongiglione, B., \& Sabater, A. (2014). The role of education at young and older ages in explaining health inequalities in Europe. Population, Space and Place, 22, 255-275.

Preston, S. H., \& Glei, D. A., et al. (2011). Contribution of smoking to international differences in life expectancy. In International differences in mortality at older ages: Dimensions and sources (pp. 105-131). 
Prossnitz, E. R., \& Maggiolini, M. (2009). Mechanisms of estrogen signaling and gene expression via GPR30. Molecular and Cellular Endocrinology, 308(1-2), 32-38.

Pudaric, S., Sundquist, J., et al. (2003). Country of birth, instrumental activities of daily living, self-rated health and mortality: A Swedish population-based survey of people aged 55-74. Social Science and Medicine, 56(12), 2493-2503.

Rantanen, T., Guralnik, J. M., et al. (1999). Midlife hand grip strength as a predictor of old age disability. JAMA, 281(6), 558-560.

Rantanen, T., Harris, T., et al. (2000). Muscle strength and body mass index as long-term predictors of mortality in initially healthy men. Journals of Gerontology. Series A, Biological Sciences and Medical Sciences, 55(3), M168-M173.

Raphael, D. (2004). Social determinants of health: Canadian perspectives. Toronto: Canadian Scholars' Press.

Razum, O., \& Twardella, D. (2002). Time travel with Oliver Twist. Tropical Medicine \& International Health, 7(1), 4-10.

Reeves, M. J., Bushnell, C. D., et al. (2008). Sex differences in stroke: Epidemiology, clinical presentation, medical care, and outcomes. The Lancet Neurology, 7(10), 915-926.

Rehm, J., Mathers, C., Popova, S., Thavorncharoensap, M., Teerawattananon, Y., \& Patra, J. (2009). Global burden of disease and injury and economic cost attributable to alcohol use and alcohol-use disorders. The Lancet, 373(9682), 2223-2233.

Reilly, D. (2012). Gender, culture, and sex-typed cognitive abilities. PLoS ONE, 7(7), e39904.

Reine, I., Novo, M., et al. (2013). Unemployment and ill health-A gender analysis: Results from a 14-year follow-up of the Northern Swedish Cohort. Public Health, 127(3), 214-222.

Rigby, J. E., \& Dorling, D. (2007). Mortality in relation to sex in the affluent world. Journal of Epidemiology and Community Health, 61(2), 159-164.

Rivera, C. M., Grossardt, B. R., et al. (2009). Increased cardiovascular mortality following early bilateral oophorectomy. Menopause (New York, NY), 16(1), 15-23.

Roberts, H. C., Denison, H. J., et al. (2011). A review of the measurement of grip strength in clinical and epidemiological studies: Towards a standardised approach. Age and Ageing, 40(4), 423-429.

Roberts, R. E., Shema, S. J., et al. (2000). Sleep complaints and depression in an aging cohort: A prospective perspective. American Journal of Psychiatry, 157(1), 81-88.

Robinson, S., \& Harris, H. (2011). Smoking and drinking among adults, 2009.

Roelfs, D. J., Shor, E., et al. (2011). Losing life and livelihood: A systematic review and meta-analysis of unemployment and all-cause mortality. Social Science and Medicine, 72(6), 840-854.

Rogers, R. G., \& Powell-Griner, E. (1991). Life expectancies of cigarette smokers and nonsmokers in the United States. Social Science and Medicine, 32(10), 1151-1159.

Roquer, J., Campello, A. R., et al. (2003). Sex differences in first-ever acute stroke. Stroke, 34(7), $1581-1585$.

Ross, M. T., Grafham, D. V., et al. (2005). The DNA sequence of the human X chromosome. Nature, 434(7031), 325-337.

Ross, C. E., Masters, R. K., \& Hummer, R. A. (2012). Education and the gender gaps in health and mortality. Demography, 49(4), 1157-1183.

Rossouw, J. E., Anderson, G. L., et al. (2002). Risks and benefits of estrogen plus progestin in healthy postmenopausal women: Principal results from the Women's Health Initiative randomized controlled trial. JAMA, 288(3), 321-333.

Ruige, J. B., Mahmoud, A. M., et al. (2011). Endogenous testosterone and cardiovascular disease in healthy men: A meta-analysis. Heart, 97, 870-875.

Rushton, J. P., \& Ankney, C. D. (2009). Whole brain size and general mental ability: A review. International Journal of Neuroscience, 119(5), 692-732.

Sandberg, K., \& Ji, H. (2012). Sex differences in primary hypertension. Biology of Sex Differences, $3(1), 7$.

Sasaki, H., Kasagi, F., et al. (2007). Grip strength predicts cause-specific mortality in middle-aged and elderly persons. The American Journal of Medicine, 120(4), 337-342. 
Schaap, L. A., Pluijm, S. M. F., et al. (2009). Higher inflammatory marker levels in older persons: Associations with 5-year change in muscle mass and muscle strength. The Journals of Gerontology Series A: Biological Sciences and Medical Sciences, 64A(11), 1183-1189.

Schooling, C. M. (2015). Could androgens be relevant to partly explain why men have lower life expectancy than women? Journal of Epidemiology and Community Health, 70, 324-328.

Schupf, N., Tang, M. X., et al. (2005). Decline in cognitive and functional skills increases mortality risk in nondemented elderly. Neurology, 65(8), 1218-1226.

Shaw, M., Maxwell, R., et al. (2004). Gender and age inequity in the provision of coronary revascularisation in England in the 1990s: Is it getting better? Social Science and Medicine, 59(12), 2499-2507.

Singh, T., \& Newman, A. B. (2011). Inflammatory markers in population studies of aging. Ageing Research Reviews, 10(3), 319-329.

Singh-Manoux, A., Gueguen, A., et al. (2007). Self-rated health and mortality: Short and long term associations in the Whitehall II Study. Psychosomatic Medicine, 69, 138-143.

Sjöström, M., Oja, P., Hagströmer, M., Smith, B. J., \& Bauman, A. (2006). Health-enhancing physical activity across European Union countries: The Eurobarometer study. Journal of Public Health, 14(5), 291-300.

Smith, G. D. (1996). Income inequality and mortality: Why are they related? BMJ. British Medical Journal, 312(7037), 987-988.

Smith, G. D., Hart, C., Hole, D., MacKinnon, P., Gillis, C., Watt, G., et al. (1998). Education and occupational social class: Which is the more important indicator of mortality risk? Journal of Epidemiology and Community Health, 52(3), 153-160.

Smith, D. B., Murphy, P., et al. (2009). Gender differences in the Colorado stroke registry. Stroke, 40(4), 1078-1081.

Solé-Auró, A., \& Crimmins, E. M. (2013). The oldest old health in Europe and the United States. Annual Review of Gerontology and Geriatrics, 33(1), 1-33.

Spolarics, Z. (2007). The X-files of inflammation: Cellular mosaicism of X-linked polymorphic genes and the female advantage in the host response to injury and infection. Shock, 27(6), 597-604.

Stahre, M. R., Roeber, J., Kanny, D., Brewer, R. D., \& Zhang, X. (2014). Contribution of excessive alcohol consumption to deaths and years of potential life lost in the United States. Preventing Chronic Disease, 11, E109.

Stampfer, M. J., \& Colditz, G. A. (1991). Estrogen replacement therapy and coronary heart disease: A quantitative assessment of the epidemiologic evidence. Preventive Medicine, 20(1), 47-63.

Stirbu, I., Kunst, A. E., et al. (2006). Differences in avoidable mortality between migrants and the native Dutch in the Netherlands. BMC Public Health, 6(1), 78.

Strandh, M., Hammarström, A., et al. (2013). Unemployment, gender and mental health: The role of the gender regime. Sociology of Health \& Illness, 35(5), 649-665.

Sundquist, J., \& Johansson, S.-E. (1997). Long-term illness among indigenous and foreign-born people in Sweden. Social Science and Medicine, 44(2), 189-198.

Sundquist, J., \& Winkleby, M. A. (1999). Cardiovascular risk factors in Mexican American adults: A transcultural analysis of NHANES III, 1988-1994. American Journal of Public Health, 89(5), 723-730.

Syddall, H., Cooper, C., et al. (2003). Is grip strength a useful single marker of frailty? Age and Ageing, 32, 650-656.

Taekema, D. G., Gussekloo, J., et al. (2010). Handgrip strength as a predictor of functional, psychological and social health. A prospective population-based study among the oldest old. Age and Ageing, 39(3), 331-337.

Tapp, A. L., Maybery, M. T., et al. (2011). Evaluating the twin testosterone transfer hypothesis: A review of the empirical evidence. Hormones and Behavior, 60(5), 713-722.

Thorslund, M., Wastesson, J., et al. (2013). The rise and fall of women's advantage: A comparison of national trends in life expectancy at age 65 years. European Journal of Ageing, 10, 1-7.

Trovato, F., \& Heyen, N. B. (2006). A varied pattern of change of the sex differential in survival in the G7 countries. Journal of Biosocial Science, 38(3), 391-401. 
Vaccarino, V., Badimon, L., et al. (2010). Ischaemic heart disease in women: Are there sex differences in pathophysiology and risk factors? Position paper from the working group on coronary pathophysiology and microcirculation of the European society of cardiology. Cardiovascular Research, 90, 9-17.

Vaccarino, V., Horwitz, R. I., et al. (1998). Sex differences in mortality after myocardial infarction: Evidence for a sex-age interaction. Archives of Internal Medicine, 158(18), 2054-2062.

Vaccarino, V., Krumholz, H. M., et al. (2001). Sex differences in 2-year mortality after hospital discharge for myocardial infarction. Annals of Internal Medicine, 134(3), 173-181.

Vaccarino, V., Lin, Z. Q., et al. (2003). Gender differences in recovery after coronary artery bypass surgery. Journal of the American College of Cardiology, 41(2), 307-314.

Vaccarino, V., Parsons, L., et al. (1999). Sex-based differences in early mortality after myocardial infarction. New England Journal of Medicine, 341(4), 217-225.

Vallin, J. (2006). Mortality, sex, and gender. In G. Caselli, J. Vallin, \& G. Wunsch (Eds.), Demography: Analysis and synthesis (Vol. II, pp. 177-194). Amsterdam, Boston, Heidelberg, London, New York, Oxford, Paris, San Diego, San Francisco, Singapore, Sydney, Tokyo: Elsevier.

van Bavel, J. (2011). The impact of a Mediterranean diet and healthy lifestyle on premature mortality in men and women. The American Journal of Clinical Nutrition, 94, 913-920.

van der Sluis, S., Posthuma, D., et al. (2006). Sex differences on the Dutch WAIS-III. Intelligence, 34(3), 273-289.

Van Oyen, H., Cox, B., et al. (2010). Gender gaps in life expectancy and expected years with activity limitations at age 50 in the European Union: Associations with macro-level structural indicators. European Journal of Ageing, 7, 229-237.

Van Oyen, H., Nusselder, W., et al. (2012). Gender differences in healthy life years within the EU: An exploration of the "health-survival" paradox. International Journal of Public Health, 58 (1), 143-155.

Verbrugge, L. M., \& Jette, A. M. (1994). The disablement process. Social Science and Medicine, $38(1), 1-14$.

Vilhjalmsson, R., \& Kristjansdottir, G. (2003). Gender differences in physical activity in older children and adolescents: The central role of organized sport. Social Science and Medicine, 56 (2), 363-374.

Virtanen, P., Vahtera, J., et al. (2008). Employment trajectory as determinant of change in health-related lifestyle: the prospective HeSSup study. The European Journal of Public Health, 18(5), 504-508.

Vitale, C., Mendelsohn, M. E., et al. (2009). Gender differences in the cardiovascular effect of sex hormones. Nature Reviews Cardiology, 6(8), 532-542.

Von Dem Knesebeck, O., Verde, P. E., \& Dragano, N. (2006). Education and health in 22 European countries. Social Science and Medicine, 63(5), 1344-1351.

Voyer, D., Voyer, S., et al. (1995). Magnitude of sex differences in spatial abilities: A meta-analysis and consideration of critical variables. Psychological Bulletin, 117(2), 250-270.

Waldron, I. (1983). Sex differences in human mortality: The role of genetic factors. Social Science and Medicine, 17(6), 321-333.

Waldron, I. (1993). Recent trends in sex mortality ratios for adults in developed countries. Social Science and Medicine, 36(4), 451-462.

Warburton, D. E., Nicol, C. W., \& Bredin, S. S. (2006). Health benefits of physical activity: The evidence. Canadian Medical Association Journal, 17(6), 801-809.

Wardle, J., Haase, A. M., Steptoe, A., Nillapun, M., Jonwutiwes, K., \& Bellisie, F. (2004). Gender differences in food choice: The contribution of health beliefs and dieting. Annals of Behavioral Medicine, 27(2), 107-116.

Weber, D., Skirbekk, V., et al. (2014). The changing face of cognitive gender differences in Europe. Proceedings of the National Academy of Sciences, 111(32), 11673-11678.

Whitacre, C. C. (2001). Sex differences in autoimmune disease. Nature Immunology, 2(9), 777-780. WHO. (2016). What are social determinants of health? Retrieved June 16, 2016. 
Wild, S. H., Fischbacher, C., et al. (2007). Mortality from all causes and circulatory disease by country of birth in England and Wales 2001-2003. Journal of Public Health, 29(2), 191-198.

Wilkinson, R. G., \& Marmot, M. G. (2003). Social determinants of health: The solid facts.

Wingard, D. L., Suarez, L., et al. (1983). The sex differentials in mortality from all causes and ischemic heart disease. American Journal of Epidemiology, 117(2), 165-172.

Wise, P. M., Dubal, D. B., et al. (2005). Are estrogens protective or risk factors in brain Injury and neurodegeneration? Reevaluation after the Women's Health Initiative. Endocrine Reviews, 26(3), 308-312.

Weichselbaumer, D., \& Winter-Ebmer, R. (2005). A meta-analysis of the international gender wage gap. Journal of Economic Surveys, 19(3), 479-511.

Xing, D., Nozell, S., et al. (2009). Estrogen and mechanisms of vascular protection. Arteriosclerosis, Thrombosis, and Vascular Biology, 29(3), 289-295.

Xu, L., Freeman, G., et al. (2013). Testosterone therapy and cardiovascular events among men: A systematic review and meta-analysis of placebo-controlled randomized trials. BMC Medicine, 11(1), 1-12.

Yaffe, K., Lindquist, K., et al. (2003). Inflammatory markers and cognition in well-functioning African-American and white elders. Neurology, 61(1), 76-80.

Yang, X.-P., \& Reckelhoff, J. F. (2011). Estrogen, hormonal replacement therapy and cardiovascular disease. Current Opinion in Nephrology and Hypertension, 20(2), 133-138.

Zajacova, A. (2006). Education, gender, and mortality: Does schooling have the same effect on mortality for men and women in the US?. Social Science and Medicine, 63(8), 2176-2190.

Zambon, A., Boyce, W., Cois, E., Currie, C., Lemma, P., Dalmasso, P., et al. (2006). Do welfare regimes mediate the effect of socioeconomic position on health in adolescents? International Journal of Health Services, 36(2), 309-329.

Open Access This chapter is licensed under the terms of the Creative Commons Attribution 4.0 International License (http://creativecommons.org/licenses/by/4.0/), which permits use, sharing, adaptation, distribution and reproduction in any medium or format, as long as you give appropriate credit to the original author(s) and the source, provide a link to the Creative Commons license and indicate if changes were made.

The images or other third party material in this chapter are included in the chapter's Creative Commons license, unless indicated otherwise in a credit line to the material. If material is not included in the chapter's Creative Commons license and your intended use is not permitted by statutory regulation or exceeds the permitted use, you will need to obtain permission directly from the copyright holder.

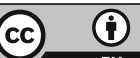

